GA-A15734

\title{
DRESDEN 1 PLUTONIUM RECYCLE PROGRAM FINAL REPORT
}

\author{
by \\ STUART D. BRESNICK
}

\author{
Prepared under \\ Contract EY-76-C-02-2210 \\ for the Chicago Operations Office \\ Department of Energy
}

DATE PUBLISHED: JANUARY 1980

\section{GENERAL ATOMIC COMPANY}




\section{DISCLAIMER}

This report was prepared as an account of work sponsored by an agency of the United States Government. Neither the United States Government nor any agency Thereof, nor any of their employees, makes any warranty, express or implied, or assumes any legal liability or responsibility for the accuracy, completeness, or usefulness of any information, apparatus, product, or process disclosed, or represents that its use would not infringe privately owned rights. Reference herein to any specific commercial product, process, or service by trade name, trademark, manufacturer, or otherwise does not necessarily constitute or imply its endorsement, recommendation, or favoring by the United States Government or any agency thereof. The views and opinions of authors expressed herein do not necessarily state or reflect those of the United States Government or any agency thereof. 


\section{DISCLAIMER}

Portions of this document may be illegible in electronic image products. Images are produced from the best available original document. 


\section{NOTICE}

This report was prepared as an account of work sponsored by the United States Government. Neither the United States nor the Department of Energy, nor any of their employees, nor any of their contractors, subcontractors, or their employees, makes any warranty, express or implied, or assumes any legal liability or responsibility for the accuracy, completeness or usefulness of any information, apparatus, product or process disclosed, or represents that its use would not infringe privately owned rights. 
GA-A15734

\title{
DRESDEN 1 PLUTONIUM RECYCLE PROGRAM FINAL REPORT
}

\author{
by \\ STUART D. BRESNICK
}

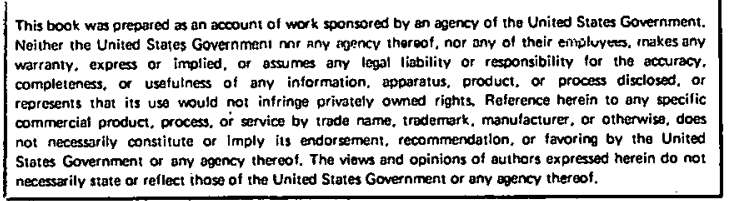

\section{Prepared under}

Contract EY-76-C-02-2210

for the Chicago Operations Office

Department of Energy

\section{GENERAL ATOMIC PROJECT 9047 \\ DATE PUBLISHED: JANUARY 1980}


THIS PAGE

\section{WAS INTENTIONALLY LEFT BLANK}


CONTENTS

1. INTRODUCTION . . . . . . . . . . . . . . 1-1

2. SUMMARY OF PROGRAM .................... 2-1

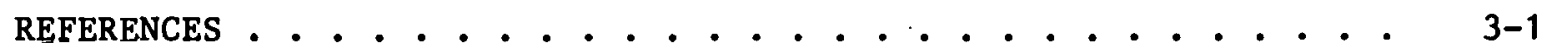

APPENDIX A: FUEL INSPECTION . . . . . . . . . . A-1

APPENDIX B: POST-IRRADIATION EXAMINATION ........ B-1

APPENDIX C: DISTRIBUTION ...................... C-1 


\section{INTRODUCTION}

This is the final report on the Dresden 1 Plutonium Recycle Demonstration Program. It covers the work performed from July 1, 1978 to completion, which includes in-pool inspection of two fuel assemblies, removal of two fuel rods, and post-irradiation examination (PIE) of six fuel rods.

Appendix A describes the inspection and rod removal operations, and Appendix B describes the PIE work. 


\section{SUMMARY OF PROGRAM}

This work was carried out under a program initiated by United Nuclear Corporation and Commonwealth Edison Company in 1967. Fuel design and fabrication was done by Gulf Nuclear Fuels Company (formerly Gulf United Nuclear Fuels Corporation and United Nuclear Corporation).

Eleven fuel assemblles, each containing nine mixed oxide $\left(\mathrm{PuU}_{2}-\mathrm{UO}_{2}\right)$ fuel rods, were designed, fabricated, and delivered as part of the Batch 7 reload fuel for Dresden 1. Irradiation of this fuel began in January 1970, and the last mixed oxide assemblles were removed from the core in January 1977.

Design and manufacture of the fuel are described in Refs. 1" through 5 ,

Performance of the assemblies was satisfactory. Details of power density and exposure history are described in the progress reports listed in Refs. 6 through 13.

After cycle 7 ( 11,000 MWd/MT heavy metal average assembly exposure), all 11 assemblies were visually inopccted (by underwater TV) and sipped for gas leakage. All assemblies were found to be in good condition and were returned to the core.

At the end of cycle 8 (October 1973), all 11 assemblies were sipped. S1x were found to be leaking and were not loaded for the next cycle. Average assembly exposure at this time was 215,900 to $17,500 \mathrm{MWd} / \mathrm{MT}$ heavy metal. Visual inspection (underwater TV) of the assemblies showed several end-plug weld failures and cladding blisters. These defects were not unique to the mixed oxide fuel; the $\mathrm{UO}_{2}$ fuel also exhibited such defects. 
At the end of cycle 9 (September 1975), two assemblies were visually inspected, and no defects or abnormalities were found. Average assembly exposure was $\sim 19,000$ to $20,000 \mathrm{MWd} / \mathrm{MT}$ heavy metal.

At this time, four mixed oxide fuel rods were removed, one from each of two assemblies removed at the end of cycle 8 and the end of cycle 9 .

At the end of cycle 10 (June 1977), the remaining mixed oxide ascemblies were remuved from the core dite to high expocure $(124,000$ to $25,000 \mathrm{MWd} / \mathrm{MT}$ heavy metal average assembly exposure). At this time, a visual inspection was made of two assembilies, and one mixed uxide rod was removed from each of these assemblies. The inspection showed no defects or abnormalities. Details of this inspection and rod removal are described in Appendix A.

The final phase of this program was the PIE of the six fuel. rods, representing three stages of fuel buruup. The PIE work was done by Babcock and Wilcox, in accordance with the scope described in the Department of Energy contract. Appendix B contains the entire Babcock and Wilcox PIE report. 


\section{REFERENCES}

1. "Dresden Plutonium Demonstration Program - Proof-Test Facility Experiments and Results," DOE Report GU-5285, Gulf United Nuclear Fuels Corporation, October 1972.

2. "PLATR Critical Experiments on Mixed-Oxide Fuel Assemblies for BWR's and Comparison with Calculations,". DOE Report GU-5289, Gulf United Nuclear Fuels Corporation, January 1973.

3. "Nuclear Design, Economics and Safety Analysis of the Dresden I Mixed Oxide Demonstration Assemblies," DOE. Report GU-5291, Gulf United Nuclear Fuels Corporation, December 1972.

4. "Mechanical Design of Dresden I Mixed Oxide Demonstration Assemblies," DOE Report GU-5292, Gulf United Nuclear Fuels Corporation, March 1973.

5. "Mixed Oxide Fuel Pellet Fabrication and Fuel Rod Assembly for Dresden I, Batch 7 Reload," DOE Report GU-5308, Gulf United Nuclear Fuels Corporation, January 1974.

6. "Semlannual Report for Period Ending June 30, 1972," DOE Report GU-5287; Gulf United Nuclear Fuels Corporation, January 1973.

7. "Semiannual Report for Period Ending December 31, 1972," DOE Report GU-5290, Gulf United Nuclear Fuels Corporation, January 1973.

8. "Semiannual:Report for Perlod Ending June 30, 1973," DOE Report GU-5304, Gulf United Nuclear Fuels Corporation, July 1973.

9. "Semiannual Report for Period Ending December 31, 1973," DOE Report GU-5309, Gulf United Nuclear Fuels Corporation, January 1974 .

10. "Dresden 1 Plutonium Recycle Report for the Period January 1, 1974 through June 30, 1975,". DOE Report GA-A13813, General Atomic Company, December 1975.

11. "Dresden 1 Plutonium Recycle Program Report for the Period July 1, 1975 through December 31, 1975," DOE Report GA-A14106, General Atomic Company, July 1976. 
12. "Dresden 1 Plutonium Recycle Program Report for the Period January 1, 1976 through June 30, 1976," DOE Report GA-A14302, General Atomic Company, January 1977.

13. "Dresden 1 Plutonium Recycle Program Report for the Period July 1 , 1976 through June 10, 1977," DOE Report GA-A14989, General Atomic Company, January 1978. 
APPENDIX A

FUEL INSPECTION

\section{A.1. SUMMARY}

This report, prepared by Nuclear Energy Services, Inc. (NES) for General Atomic Company (GA), presents the results of the PlutoniumBearing Fuel Assembly Visual Inspection and Fuel Rod Removal Programs performed by.NES, at the Commonwea1th Edison Company Dresden 1 Nuclear Power Station. Visual inspection of the two fuel assemblies revealed no structural defects or abnormalities which would affect the normal operation of the fuel assembly in subsequent cycles. One fuel rod was removed from each fuel assembly and stored in a fuel rod storage basket in the Dresden 1 fuel storage pool.

\section{A.2. INTRODUCTION}

During the week of January 9, 1978, NES performed nuclear field services for GA at the Dresden 1 Nuclear Power Station. Two plutoniumbearing fuel assemblies were visually inspected with binoculars, and one plutonium-bearing removable fuel. rod was removed from each fuel assembly and stored in a storage basket.

\section{A. 3. PROCEDURES}

Fucl handling, visual inspection, and fuel rod removal procedures were performed in accordance with NES Document No. 8040707. All visual observations were recorded on visual inspection data sheets, which are included at the end of this report. 'Removable fuel rod transfers to the fuel rod storage basket were documented on the fuel rod storage basket key, which is also included at the end of this report. 


\section{A.4. EQUIPMENT}

\section{A.4.1. Visual Inspection Equipment}

The fuel assemblies were supported horizontally on the Commonwealth Edison Company saw table in the Dresden 1 fuel storage pool. The visual inspections were performed with Sears binoculars, 7 x 35, Extra Wide Angle. The fuel assembly was supported $14 \mathrm{ft}$ from the inspector.

\section{A.4.2. Fuel Rod Removal Equipment}

The GA removable fuel rod handling tool and fuel rod storage basket were used for fuel rod removal and storage. The two Commonwealth Edison Company sipper-strippers were used to support the fuel assembly and the fuel rod storage basket during fuel rod removal operations. All fuel assembly transfers in the pool were performed by Commonwealth Edison Company personnel using the fuel handling machine.

\section{A.5. RESULTS}

\section{A.5.1. Visual Inspection Results}

Detailed visual examination of the two plutonium-bearing fuel assemb1ies, UN-098 and UN-101, revealed no structura1 defects or abnormalities which would affect the normal operation of the fuel assemblies in subsequent cycles. The assemblies were free of any visual bowing; all spacer grids were found to be sound and uncocked.* Equal spacing and seralghtness of all vioully aceesaible fuel rods.were observed.

* The cocked spacer observed on Fuel Assembly No. UN-098 probably occurred during insertion of the fuel assembly into the saw table. The fuel handlers experienced some difficulty during the insertion of this fuel assembly into the saw table. The cocked spacer, however, did not preclude the proper installation of the shroud on the fuel assembly when reassembled after the visual inspection. 
In addition, there were no visible indications of clad defects due to pellet-clad interactions. Crud patterns observed were considered normal.

The raw visual inspection data sheets are included at the end of this report.

\section{A.5.2. Fuel Rod Removal Results}

Forces required for breaking the fuel rods away from the spacers and forces required for withdrawal were considered normal for the two fuel rods removed. The two rods were removed and stored in the fuel rod storage basket, which will be stored in the Dresden 1 storage pool fuel assembly racks until further notice by GA. The fuel assemblies from which the two fuel rods were removed, their position within the fuel assemblies, and their present positions in the fuel rod storage basket are listed in Table A-1. The fuel rod storage basket key is included at the end of this report. 
TABLE A-1

DISPOSITION OF FUEL RODS REMOVED FROM

PLUTONIUM-BEARING FUEL ASSEMBLIES

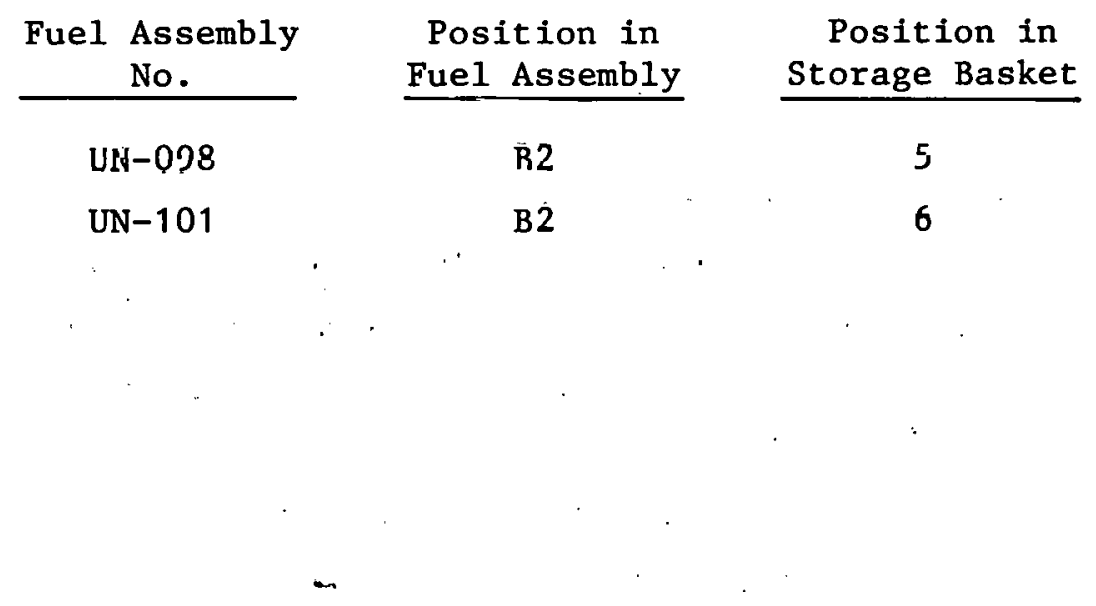

A-4 
NUCLEAR ENERGY SERVICES, INC NES DIVISION

VISUAL INSPECTION DATA SHEET
Fuel Assembly No. UN-

Exposure

Video Tape No. NA

Index No. NA To NA

Operator

Inspector LOU ZEZZA
Date $1-11-78$

Time Start 1010

Time Finish 1020

Approved -

Date

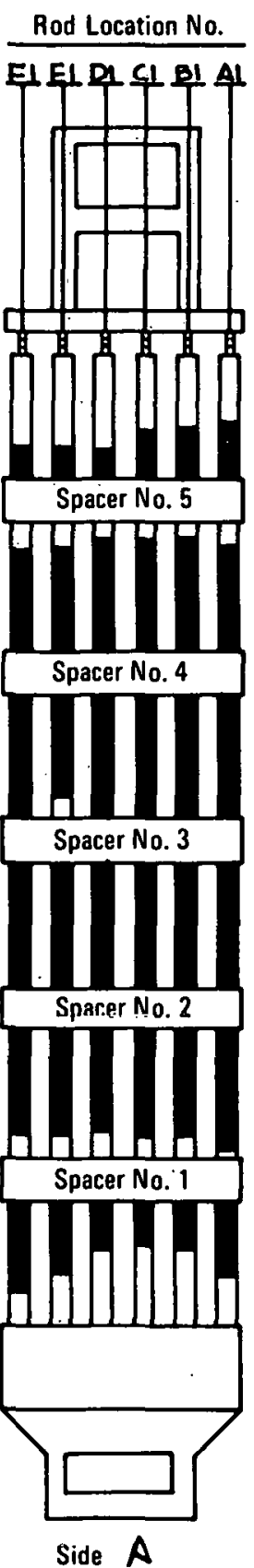

1

1. All Nuts Crimped

Remarks

2. Rem. Rod Locked Remarks

\section{Check List}

Yes

-

3. All Springs Assembled Remarks.

4. Spacer Damage Remarks

5. Free End Rods Bottomed-Out Remarks

6. Bowed Rods

Remarks
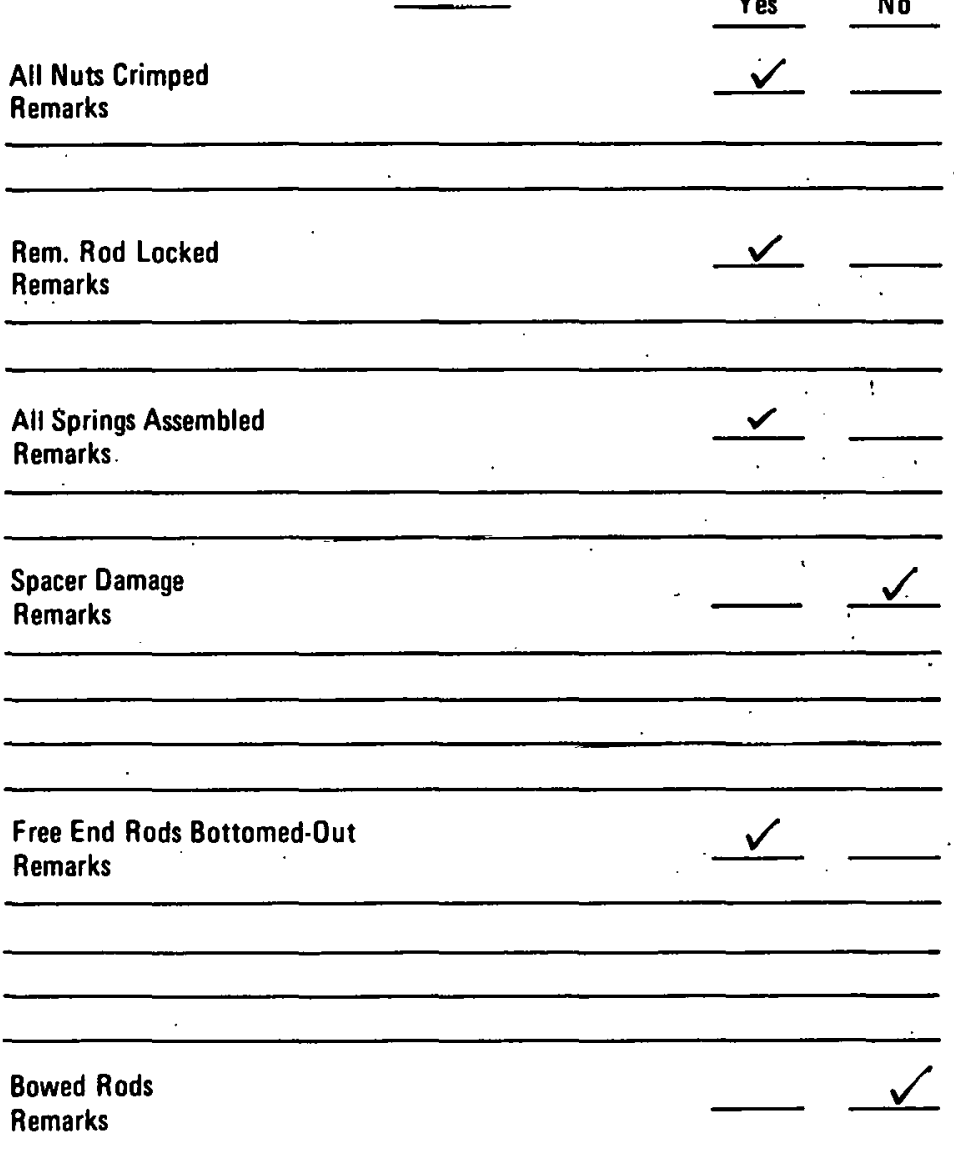

7. Miscellaneous Observations Remarks UNSHSDES $\triangle R E A S$ ARE CAUD FAEE. 


\begin{tabular}{|c|c|c|}
\hline & Fuel Assembly No. UN-O98 & Date $1-11-78$ \\
\hline NUCLEAR ENERGY SERVICES, INC. & Exposure & Time Start $\quad 0945$ \\
\hline & Video Tape No. NA. & Time Finish 0955 \\
\hline 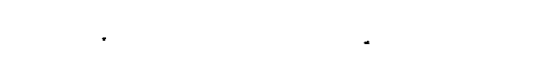 & $\begin{array}{l}\text { Index No. NA To NA } \\
\text { Operator }\end{array}$ & Annroved - \\
\hline VISUAL INSPECTION DATA SHEET & Inspector $\perp O U$ ZEZZA & Date $\quad-$ \\
\hline
\end{tabular}

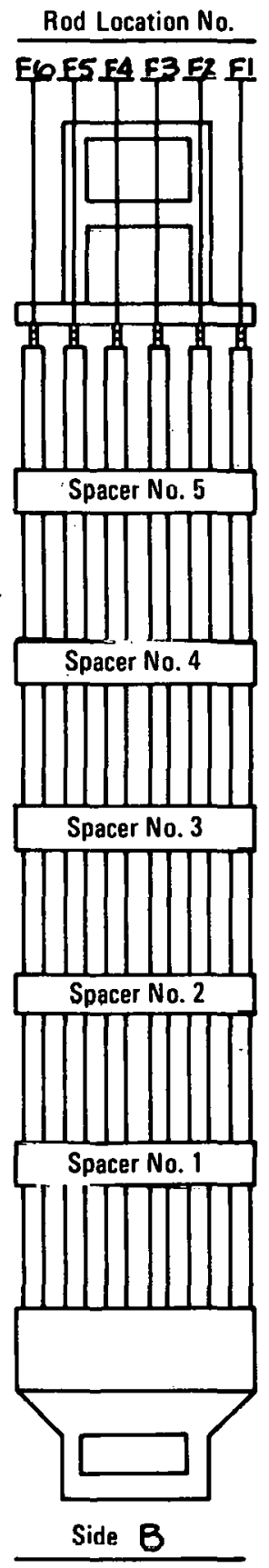

1. All Nuts Crimped Remarks

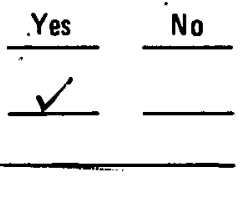

2. Rem. Rod Locked Remarks

3. All Springs Assembled Remarks

4. Spacer Damage Remarks

5. Free End Rods Bottomed-Out Remarks

6. Bowed Rods Pemarks

7. Miscellaneous Observations Remarks

a. E4 NUT RAISED $1110^{\circ}$ ABONE GRIP PIDTE b. CRUP PATTERNS $\triangle R E$ SIMILAR TO HDE A 
NUCLEAR ENERGY SERVICES, INC. NES DIVISION

VISUAL INSPECTION DATA SHEET
Fuel Assembly No. UN-098

Exposure

Video Tape No. NA

Index No. NA To NA

Operator

Inspector LOS ZEZZA
Date $1-11 \cdot 78$

Time Start 0925

Time Finish 0940

Approved -

Date

-

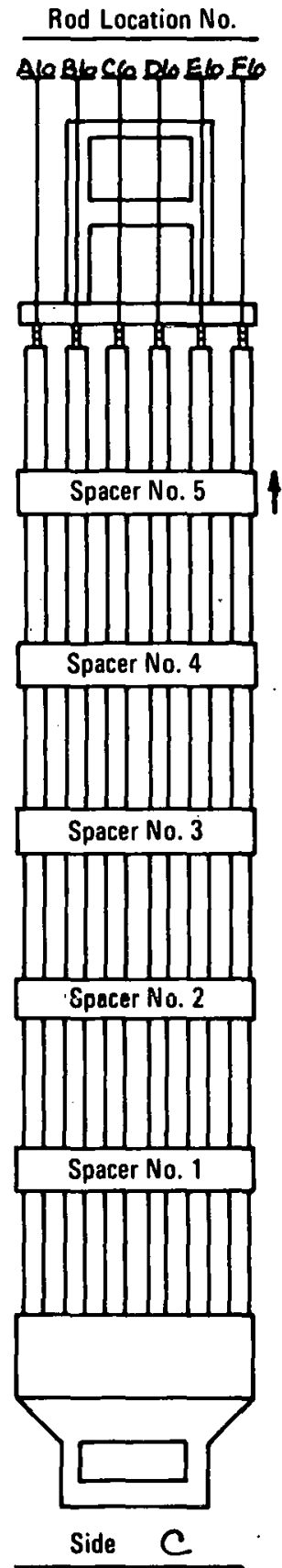

1. All Nuts Crimped Remarks

Check List

Yes. No

2. Rem. Rod Locked Remarks

3. All Springs Assembled Remarks

4. Spacer Damage Remarks

SPACER NO. 5 COKKEP DBOUT $/ \mathrm{B}^{\prime \prime} \mathrm{N}$

DIRECTON SHOWN-PROBNBLY OCCURBED DINBING INSERTION INTO SAN TABLE?

5. Free End Rods Bottomed-Out

Remarks

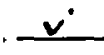

6. Bowed Rods Remarks

Miscellaneous Observations Remarks

2. DS NUT LIFIED $1 / 8^{\prime \prime}$ ABOVE GRIP PLATE b. CRUP PATERRNS ARE SIMILAR TOSIDE A 
NUCLEAR ENERGY SERVICES, INC NES DIVISION

VISUAL INSPECTION DATA SHEET
Fuel Assembly No. UN.

Exposure

Video Tape No. NA

Index. No. NA To NA

Operator

Inspector LWU ZEZZA
Date $\frac{1-11-78}{20}$

Time Start 0900

Time Finish 0915

Approved -

Date +

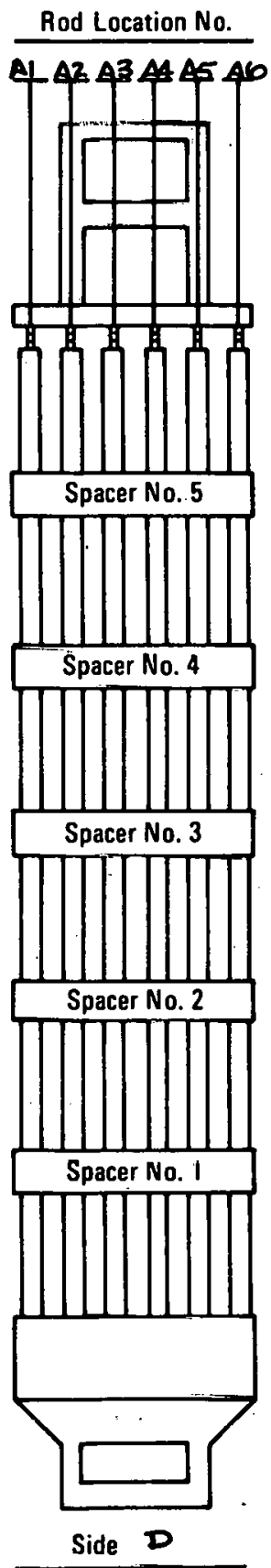

1. All Nuts Crimped

Remarks

\section{Check List}

Yes No

2. Rem. Rod Locked Remarks

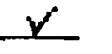

Remarks

3. All Springs Assembled Remarks

4. Spacer Damage Remarks

5. Free End Rods B̈ottomed-Uut Remarks

6. Bowed Rods Remarks

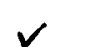

1. Miscellaneous Observations Remarks

a. B3 NUT RAKSD $1 / 8$ " ASOVE GRID PUATE b. CRUD PATIERNS ARE FMILAR TO SIDEA 
NUCLEAR ENERGY SERVICES, INC NES DIVISION

VISUAL INSPECTION DATA SHEET
Fuel Assembly No. $1 \mathrm{NL}-101$

Exposure -

Video Tape No. NA

Index No. NA

Operator

Inspector LOU ZEZZA
Date $1-11-78$

Time Start 1115

Time Finish 1120

Approved -

Date -

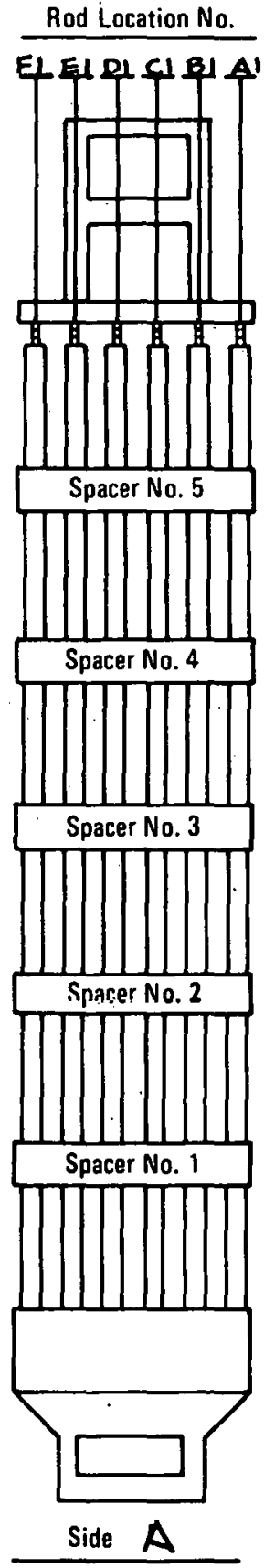

1. All Nuts Crimped

Remarks

Check List

Yes No

2. Rem. Rod Locked Remarks

3. All Springs Assembled Remarks

4. Spacer Damage Remarks

5. Free End Rods Bottomed-Out Remarks Remarks
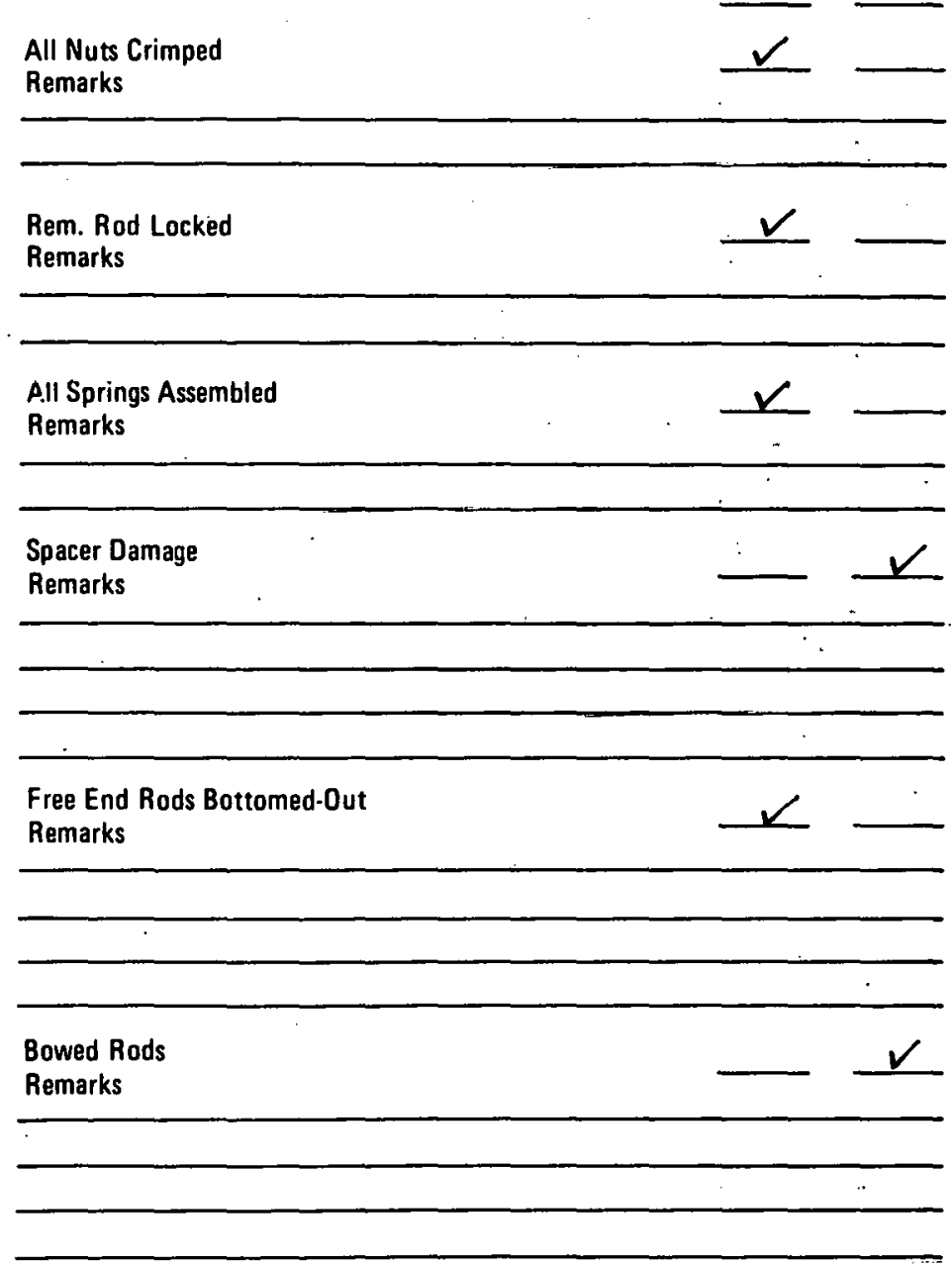

7. Miscellaneous Observations Remarks

CRUO PAIIERNS ARE SIMILAR TI SIDEA ON UN-09B 
NUCLEAR ENERGY SERVICES, INC. NES DIVISION

VISUAL INSPECTION DATA SHEET
Fuel Assembly No. UN-101

Exposure -

Video Tape No. NA

Index No. NA To NA

Operator

Inspector LQU ZEDAO
Date $1-11-78$

Time Start 1130

Time Finish 1135

Approved -

Date

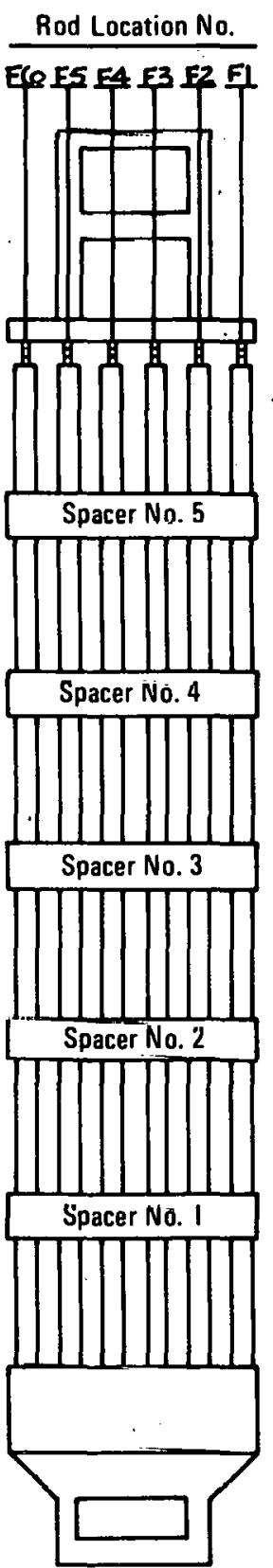

Side $B$

1. All Nuts Crimped

Hemariks

Check List

Yes No

2. Rem. Rod Locked Remarks

3. All Springs Assembled Remarks

4. Spacer Damage Remarks
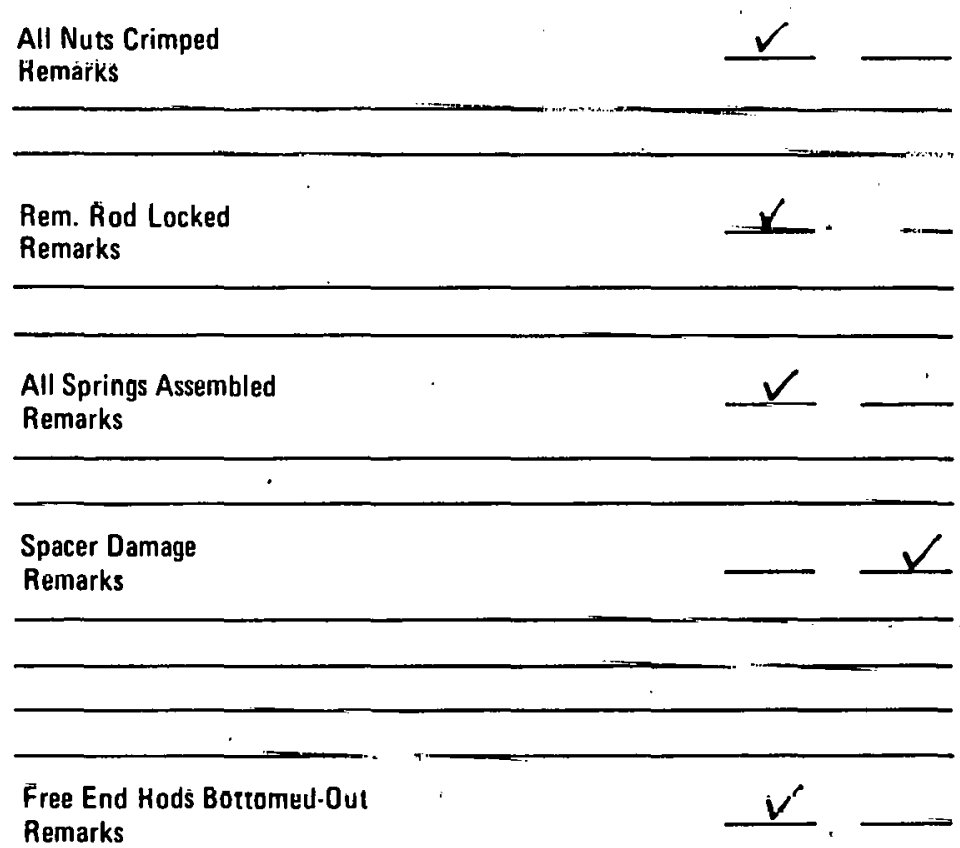
Remarks

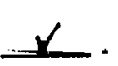

- 


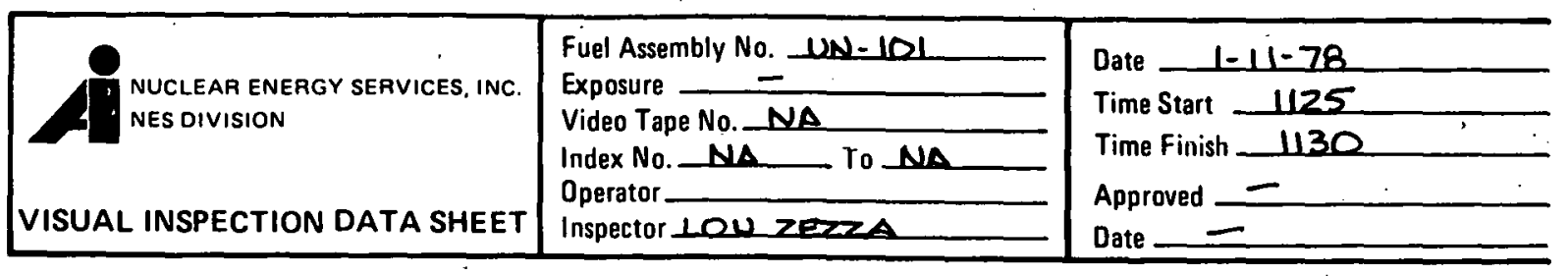

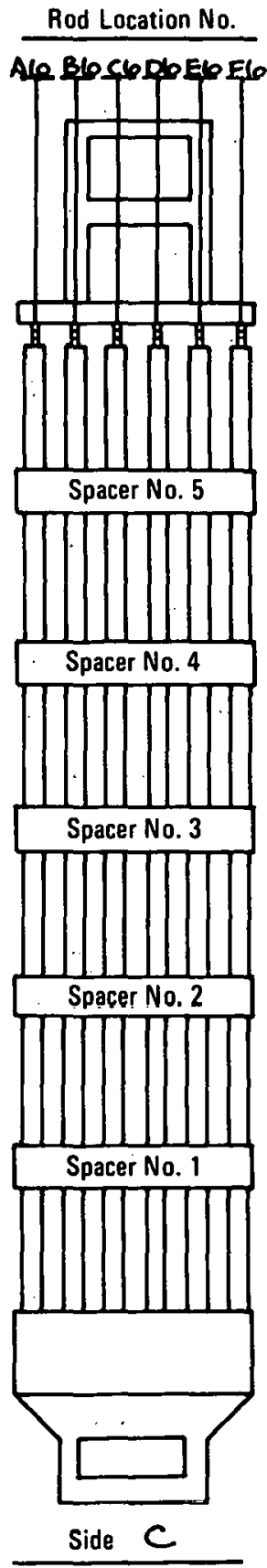

1. All Nuts Crimped

Check List

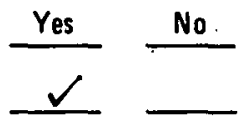

Remarks

Rem. Rod Locked Remarks

3. All Springs Assembled Remarks

4. Spacer Damage

Remarks

5. Free End Rods Bottomed-Out Remarks

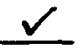

Bowed Rods

Remarks

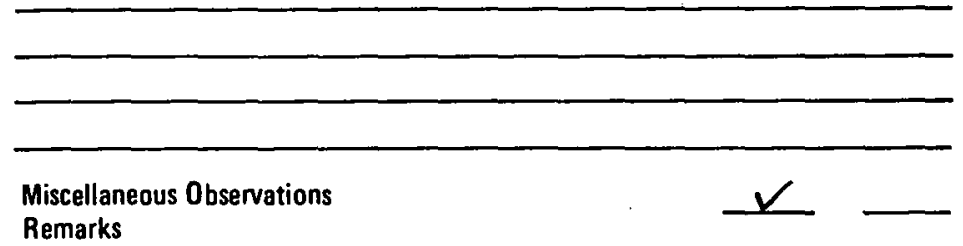

Remarks

CBUD PATIERNS ARE SIMILAR TO SIDEA 
NIJCLEAR ENERGY SERVICES, INC NES DIVISION

VISUAL INSPECTION DATA SHEET
Fuel Assembly No. $U N-101$

Exposure

Video Tape No. NA

Index No. NA To NA

Operator

Inspector LOU ZEZZA
Date $1-11.78$

Time Start 1120

Time Finish 1125

Approved -

Date _ -

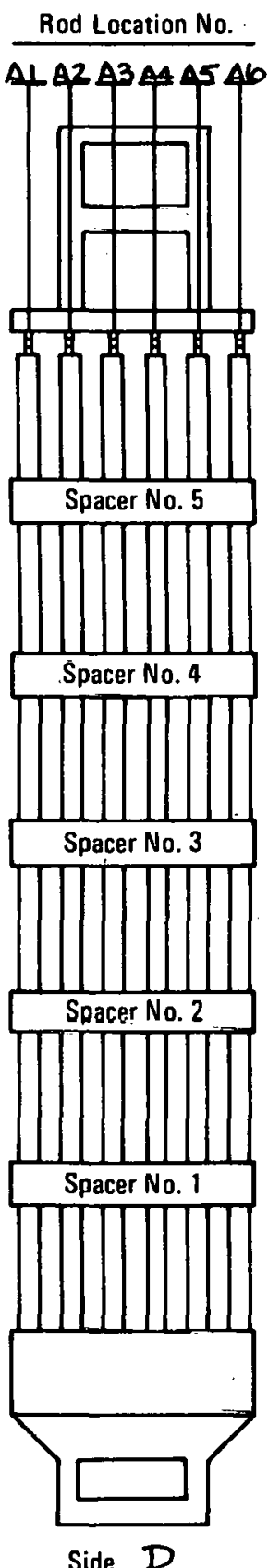

1. All Nuts Crimped Remarks

\section{Check List}

Yes No

2. Reml. Rod Locked Remarks

3. All Springs Assembled Remarks

4. Spacer Damage Remarks
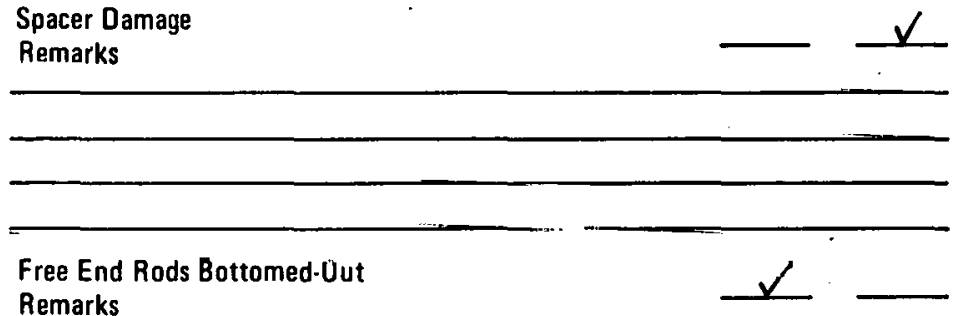
Remarks

AL RAISED $~ 1 / 10^{n}$

6. Bowed Rods Remarks
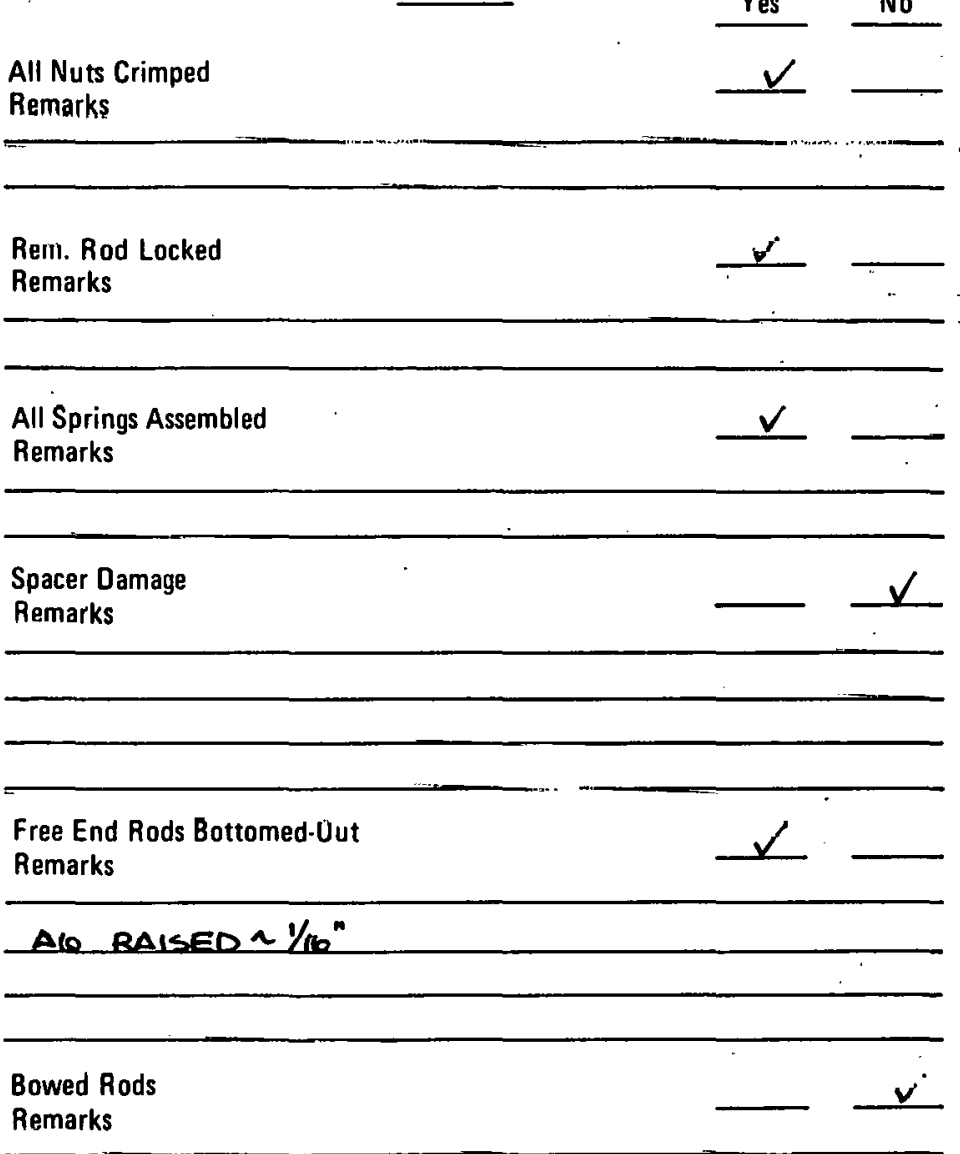

Miscellaneous Observations Remarks

a. 83 : B4 NUTS RAISED $1 / 16 "$

b. CRUD PATIERNS ARESIMILAR OSIDEA 


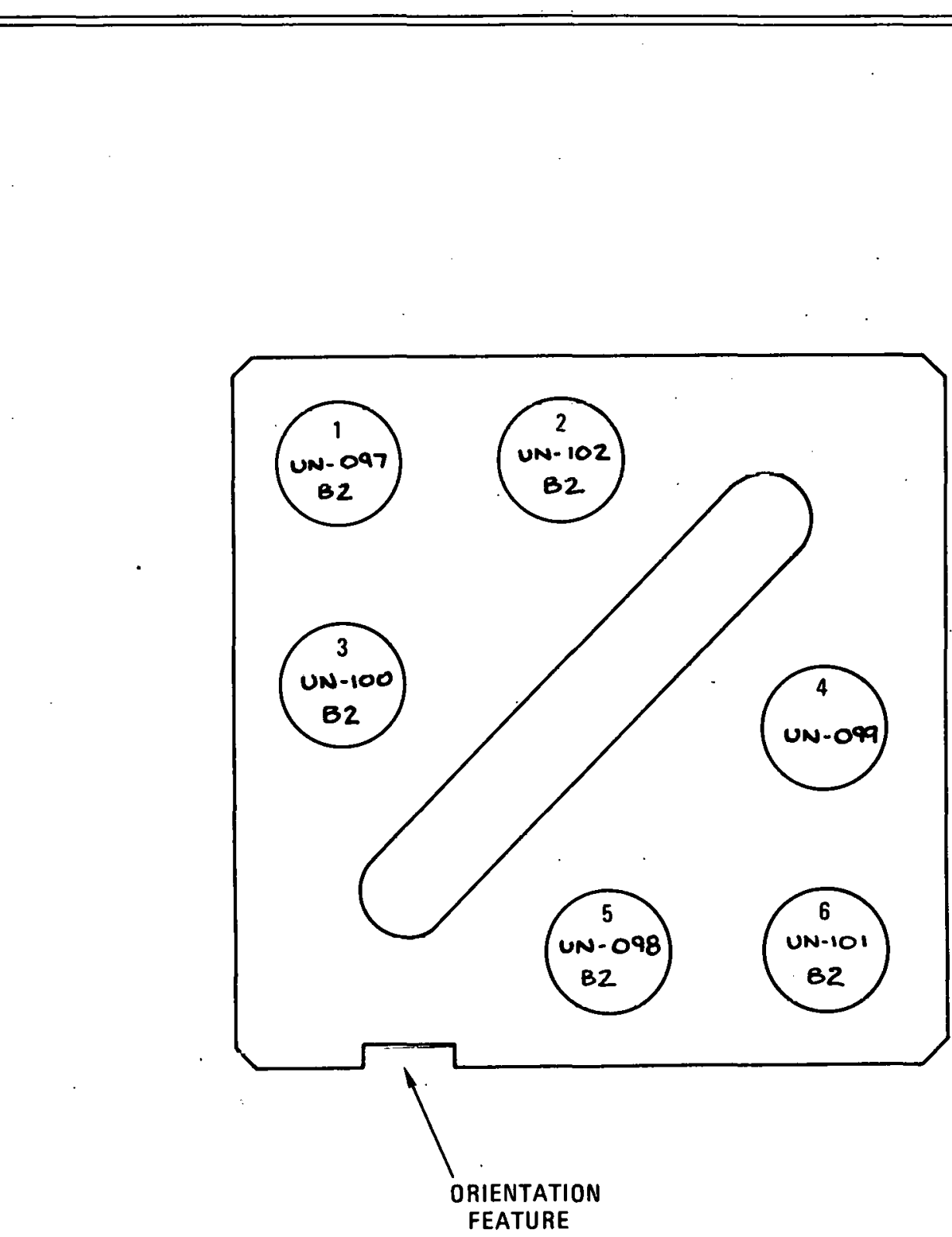

$$
\text { FEATURE }
$$

FUEL ROD STORAGE BASKET KEY 
APPENDIX B

POST-IRRADIATION EXAMINATION 

MIXED OXIDE FUEL RODS 
LEGAí' NOTICE

This report was prepared by The Babcock \& Wilcox Company for General Atomic Company and neither The Babcock \& Wilcox Company; nor any of its subcontractors, nor any person acting on behalf: of either:

a. Makes any warranty or representation, express or implied, with respect to the accuracy. completeness, or usefulness of the information contained in this report, or that the use of any: information, apparatus, method, or process disclosed in this report may not infringe privately owned rights; or

b: Assumos any liabilities ...with respect to the use of, or for damages resulting from the use of, any information, apparatus," method or process disciosed. in this report. 
This report was prepared by The Babcock \& Wi.lcox Company for General Atomic Company and neither The Babcock \& Wilcox Company, nor any of its subcontractors, nor any person acting on behalf of either:

a. Makes any warranty or representation, express or implied, with respect to the accuracy, completeness, or usefulness of the information contained in this report, or that the use of any information, apparatus, method, or process disclosed in this report may not infringe privately owned rights; or

b. Assumes any liabilities with respect to the use of, or for damages resulting from the use of, any information. apparatus, method or process disclosed in this report. 


\author{
by \\ Vishnu Subrahmanyam, \\ Todd L. Hardt, \\ Joyce St. John \\ LRC \\ Prepared for \\ General Atomic Company \\ Under G.A.C. P.0. \#619004 \\ B\&W CRD 3038
}

\author{
Submitted by \\ The Babcock \& Wilcox Company. \\ Contract Research Division \\ P. 0. Box 835 \\ Alliance, Ohio
}


THIS PAGE

\section{WAS INTENTIONALLY LEFT BLANK}




\section{ACKNOWLEDGMENT}

The assistance of Harold Collins, Dan Miller, and the Hot Cell Operations crew in conducting the gamma scans and rod sectioning is gratefully acknowledged. 


\section{SUMMARY}

Post-irradiation examination of three pairs of mixed oxide fuel ruds was con-ducted by nondestructive gamma scan and radiochemical analys is methods.

The gross gamma scans indicated that there were no major changes in the physical form of the fuel pellets due to irradiation. Axial migration of fission pruducts was ruled out hased on the absence of areas of high activity, particularly at the interpellet regions.

It is known that relative fuel burnup profiles are represented by the concentrations of primary fission products. Relative fuel burnup profiles were constructed with the aid of axial distributions of fission products determined by analyzing gamma spectra recorded at different axial locations.

The distribution of long-lived ${ }^{137} \mathrm{Cs}\left(T_{\frac{1}{2}}=30.1 \mathrm{y}\right)$ representing the fuel burnup profile for the entire irradiation period indicated the maximum burnup to be located between 100 and $135 \mathrm{~cm}$ from the bottom of the fuel stack.

Axial distributions of ${ }^{106} \mathrm{Ru}\left(T_{i_{1}}=368 \mathrm{~d}\right)$ and ${ }^{95} \mathrm{Zr}\left(T_{l_{1}}=64.0 \mathrm{~d}\right)$ represent fuel burnup (power rating) profiles during portions of irradiation and late-inlife, respectively. These profiles suggested higher rates of fiel burnup in regions away from the center of the fuel rods. The axial relative neutron flux profile deduced from the distribution of ${ }^{13^{11}} \mathrm{Cs}\left(T_{\frac{1}{2}}=2.06 \mathrm{y}\right)$ activity was different for each fuel rod.

Expressions were derived for time-averaged neutron fluxes and their squared values in terms of relative activity ratios of ${ }^{344} \mathrm{Cs} /{ }^{137} \mathrm{Cs}$ and the relative activity of ${ }^{134} \mathrm{Cs}$, respectively.

The relative profiles of fuel burnup were translated into absolute profiles by utilizing radiochemical data from two positions on each rod. 


\section{CONTENTS}

Page

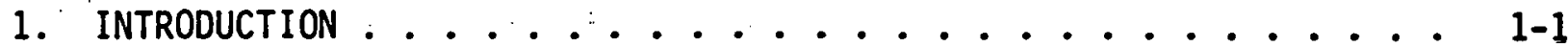

2. PROBLEM STATEMENT AND METHODS OF ANALYSIS . . . . . . . . . 2-1

2.1. Analytical Approach ................ 2-1

2.2. Experimental Approach ................. 2-3

2.2.1. Gamma Scan Method ............... 2-3

2.2.2. Destructive Method .............. 2-4

3. EXPERIMENTAL DETAILS ......................... 3-1

3.1. Gamma Scan Method .................. 3-1

3.2. Rod Sectioning Operations . . . . . . . . . . . 3-1

3.3. Destructive Method . ................. 3-2

4. RESULTS .......................... . . . 4-1

4.1. Gamma Scan Method ................ 4-1

4.2. Radiochemical Analyses ............... 4-1

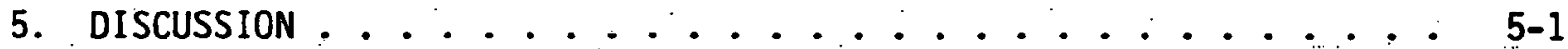

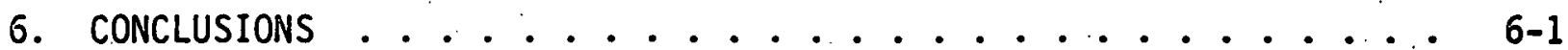

7. REFERENCES ....................... . . . . . .

\section{List of Tables}

Table

1. Identification and Location of Samples for Burnup Analysis . . 3-3

2. Relative Axial Concentrations of Fission Products in

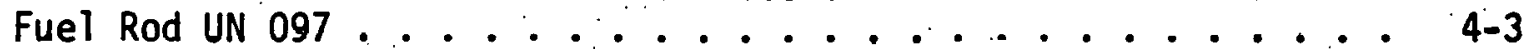

3. Relative Axtal Concentrations of Fission Products in

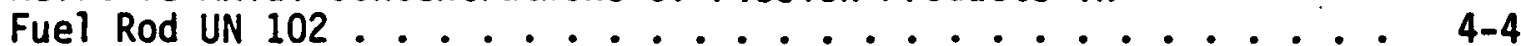

4. Relative Axial Concentrations of Fission Products in

Fuel Rod UN 098 ......................... 4-5

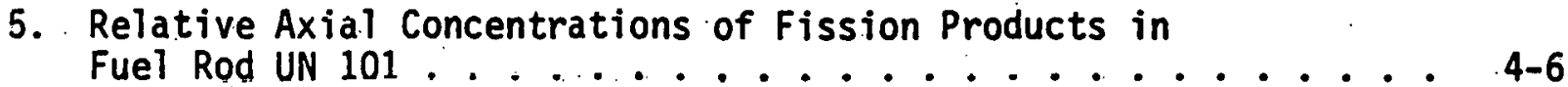




\section{Tables (Cont'd)}

Table

Page

6. Relative Axial Concentrations of Fission Products in

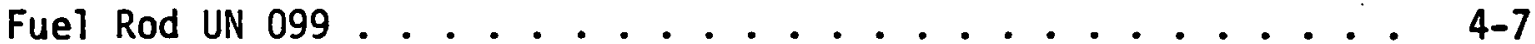

7. Relative Axial Concentrations of Fission Products in Fuel Rod UN 100 ..................... . . . 4-8

8. Atomic Composition of Mixed Oxide Fuel Samples . . . . . . . 4-9

9. Absolute Fuel Burnup and Conversion Factors for Mixed Oxide Fuel Rods . . . . . . . . . . . . . . . . . 5-4

\section{List of Figures}

Figure

1. Rod Sectioning Diagram for Dresden Rods UN U97 and UN 098 . : 3-4

2. Rod Sectioning Diagram for Dresden Rods UN 099, UN 100,

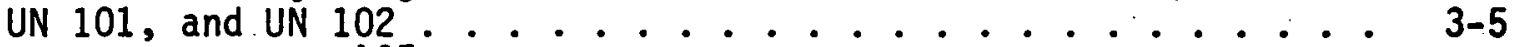

3. Gross Gamma and ${ }^{137}$ Cs Activity Scans of Fuel Rods UN 097, UN 098, and UN 099 ..................... 4-10

4. Gross Gamma and ${ }^{137}$ Cs Activity Scans of Fuel. Rods UN 100, UN 101, and UN 102 .................... 4-11

5. Scans of $95 \mathrm{Zr}$ Activity in Fuel Rods UN 098 and UN 101 . . . . 4-12

6. Relative Activities of ${ }^{137} \mathrm{Cs},{ }^{1.06} \mathrm{Ru}$ and Activity Ratio ${ }^{138} \mathrm{Cs} /{ }^{137} \mathrm{Cs}$ for Rod UN $097 . . . . . . . . . . . . .13$

7. Relative Activities of ${ }^{137} \mathrm{Cs}, 106 \mathrm{Ru}$ and Activity Ratio ${ }^{13{ }^{4} \mathrm{Cs} /{ }^{137} \mathrm{Cs} \text { for Rod UN } 102 . . . . . . . . . . . . . . . ~ 4-14 ~}$

8. Relative Activities of ${ }^{137} \mathrm{Cs}, 106 \mathrm{Ru}$ and Activity Ratio

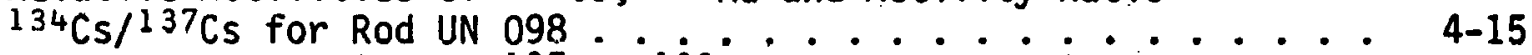

9. Relative Activities of ${ }^{137} \mathrm{Cs}, 106 \mathrm{Ru}$ and Activity Ratio ${ }^{134} \mathrm{Cs} /{ }^{137} \mathrm{Cs}$ for Rod UN 101 ................. 4-16

10. Relative Activities of ${ }^{137} \mathrm{Cs},{ }^{106} \mathrm{Ru}$ and Activity Ratio

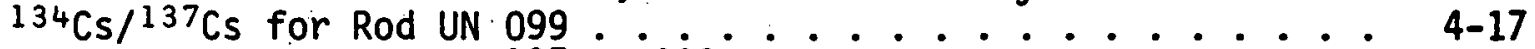

11. Relative Activities of ${ }^{137} \mathrm{Cs}, 106 \mathrm{Ru}$ and Activity Ratio $13{ }^{4} \mathrm{Cs} / 137 \mathrm{Cs}$ for Rod UN $100 \ldots$ 4-18

12. Irradiation Histories and Growth Periods of Short-Lived Isotopes Detected 


\section{INTRODUCTION}

Post-irradiation examination (PIE) of mixed oxide fuel elements is a requirement for determining the inventory of remaining fissionable material. Far more important reasons for a PIE are to develop an understanding of the characteristics of fuel burnup, and the identification and evaluation of all the parameters and their influences on controlled fission. Information of this nature is of great importance in the development and incorporation of scientific and technological improvements for fuel performance. For example, any ma.jor physical changes in fuel pellets and rods brought about by prolonged exposure to high neutron fields need thorough investigation prior to undertaking any corrective measures.

The above objectives can be achieved by both nondestructive and destructive analyses. The former is a passive method that is widely practiced ${ }^{1-3}$. because of its desirable aspects. The destructive method, on the other hand, is based on proven chemical techniques but fraught with hazards because of the high radiation fields involved. Both of these techniques are employed in the present study to investigate irradiated mixed oxide fuel rods.

Six Dresden mixed oxide fuel rods were selected by the General Atomic Corporation for post-irradiation examination. Examination of these rods was performed by The Babcock \& Wilcox Company's Lynchburg Research Center under Purchase Order 619004.

The six fuel elements were obtained in three pairs with different irradiation histories, each pair coming from irradiations ending in October 1973, August 1975, and December 19.77.

The following analyses were requested by General Atomic Corporation for each of the six rods:

1. Gross garma scan for calculation of axial burnup profile, a gamma scan for $95 \mathrm{Zr}-{ }^{95} \mathrm{Nb}$ to obtain a measure of late-in-1ife burnup and a gamma scan for ${ }^{137} \mathrm{Cs}$. Analyze scans to determine burnup profile as a function of irradiation history and possible fisston product migration. 
2. Radiochemical analysis of two sections of each rod to determine:

a. $\mathrm{U}$ and $\mathrm{Pu}$ isotopic abundances.

b. ${ }^{237} \mathrm{~Np}, 243 \mathrm{Am}$, and ${ }^{241} \mathrm{Am}$ content.

c. Burnup in each section from the atomic ratios of $239 \mathrm{pu}$ to $238 \mathrm{U}$ and ${ }_{148} \mathrm{Nd}$ to $238 \mathrm{U}$ and absolute axial burnup profiles by correlating the gross gamma scan with these data.

This report presents the problem definition, analytical approach, and experimental details used to carry out the desired workscope. The results are then presented from both nondestructive and destructive methods and discussed on a comparative basis. Conclusions and recommendations for future work constitute the final section. 


\section{PROBLEM STATEMENT AND METHODS OF ANALYSIS}

The neutron field set up by the self-sustained fission that is the source of energy for power generation in a nuclear reactor is also accompanied by some parasitic effects. These effects include neutron absorption by unused fuel and by stable fission products. Neglecting parasitic nuclear reactions, the fuel burnup rate depends on the neutron flux at any given time and location in a reactor and energy release is associated essentially with fission processes. Analysis of different portions of irradiated fuel rods for fission products and products from non-fission modes of fuel consumption provides information that is of vital importance in understanding fuel burnup and its proper utilization.

\subsection{Analytical Approach}

The mathematical treatment of nuclear fuel consumption is essentially identical to the study of a radioactive decay series starting from an initially pure parent provided an appropriate decay constant is assigned to the disappearance of fissionable atoms. ${ }^{4}$ in the decay series

$$
\mathrm{A} \stackrel{\lambda_{a}}{\longrightarrow} \mathrm{B} \stackrel{\lambda_{b}}{\longrightarrow} \mathrm{C} \stackrel{\lambda_{c}}{\longrightarrow}
$$

where A represents a nucleus undergoing fission.

The decay constant $\lambda_{a}$ is given by

$$
\lambda_{a}=\Sigma\left(\phi_{f}\right)_{i} .
$$

$\Sigma$ is the microscopic fission cross-section (in $\mathrm{cm}^{2}$ ) and $\left(\phi_{f}\right)_{i}$ is the neutron flux (neutrons $/ \mathrm{cm}^{2}-5$ ) experienced by atoms of $A$ at location $i$. In the case of mixed oxide fuel, $\Sigma$ can be expressed following Tsuruta, et al., 5 as

$$
\Sigma=n_{1} \sigma_{1}+n_{2} \sigma_{2}
$$

where $n_{1}, n_{2}$, and $\sigma_{1}, \sigma_{2}$ represent the mole fractions and fission cross sections, respectively, of the constituent fissionable fuel materials. 
The quantities $\lambda_{b}$ and $\lambda_{c}$ in equation 1 are the radioactive decay constants of the daughter and granddaughter of fission. These are approximately modified, if necessary, for modes of disappearance of atoms of $B$ and $C$ in addition to radioactive decay. Thus,

$$
\lambda_{b}=\lambda_{b} \text { (radioactive decay) }+\sigma_{a} \phi_{i}
$$

where $\sigma_{a}$ is the neutron absorption cross section of $B$ and $\phi$ is the neutron flux at location $i$.

In the cases of fission products ${ }^{137} \mathrm{Cs},{ }^{106} \mathrm{Ru}$, and $95 \mathrm{Zr}$, the neutron absorption term of equation 5 is negligible because of very small $\sigma_{a}$ values and/or due to large radioactive decay constants. On the other hand, for a stable fission product such as $1^{33} \mathrm{Cs}, \lambda_{b}$ is totally due to ncutron absorption.

The activities of $B$ and $C\left(N_{b} \lambda_{b}, N_{c} \lambda_{c}\right)$ following an irradiation for time, $T$, and at the end of a decay period, $t$, can be written ${ }^{4}$ in the following manner:

$$
\begin{aligned}
N_{b} \lambda_{b}= & \frac{A_{0} \lambda_{a} \lambda_{b}}{\left(\lambda_{b}-\lambda_{a}\right)}\left(e^{-\lambda_{a} T}-e^{-\lambda_{b} T}\right] e^{-\lambda_{b} t} \\
N_{c} \lambda_{c}= & \frac{A_{0} \lambda_{a} \cdot \lambda_{b} \cdot \lambda_{c} \cdot e^{-\lambda_{c} t}}{\left(\lambda_{a}-\lambda_{b}\right)\left(\lambda_{b}-\lambda_{c}\right)\left(\lambda_{c}-\lambda_{a}\right)} \cdot\left[\left(\lambda_{c}-\lambda_{b}\right) e^{-\lambda_{a} T}+\left(\lambda_{a}-\lambda_{c}\right) e^{-\lambda_{b} T}\right. \\
& \left.+\left(\lambda_{b}-\lambda_{a}\right) e^{-\lambda_{c} T}\right]
\end{aligned}
$$

In equations 5 and $6, A_{0}$ is the number of atoms of $A$ at time $T=0$ with $B=$ $\mathrm{c}=0$.

From equation 5 , the ratio of activitios of $B$ at locations $i$ and $j$ is given by

$$
R_{b}=\frac{\left(N_{b} \lambda_{b}\right)_{i}}{\left(N_{b} \lambda_{b}\right)_{j}}=\frac{\left(A_{o} \lambda_{a}\right)_{j}}{\left(A_{o} \lambda_{a}\right)_{j}} \text {. }
$$

Thus, $R_{1.37}, R_{106}$, and $R_{95}$ represent the relative fuel burnup values and relative activities of fission products ${ }^{137} \mathrm{Cs},{ }^{106} \mathrm{Ru}$, and ${ }^{95} \mathrm{Zr}$, respectively. Again, from equation 6 


$$
R_{c}=\frac{\left(N_{c} \lambda_{c}\right)_{j}}{\left(N_{c} \lambda_{c}\right)_{j}}=\frac{\left(A_{o} \lambda_{a} \lambda_{b}\right)_{i}}{\left(A_{o} \lambda_{a} \lambda_{b}\right)_{j}}
$$

In the specific case of ${ }^{134} \mathrm{Cs}$, substituting for $\lambda_{a}$ in equation 8 ,

$$
R_{134}=\frac{\left(\phi_{f}\right)_{j} \phi_{i}}{\left(\phi_{f}\right)_{j} \phi_{j}} \approx \frac{\phi_{i}^{2}}{\phi_{j}^{2}} .
$$

The approximation in equation 9 implies that the fissioning nucleus and the fission product ${ }^{133} \mathrm{Cs}$ experience the same neutron flux at both locations $i$. and j.

It can be seen then from equations 7 and 8 that

$$
R_{134}=R_{137} \cdot \frac{\phi_{i}}{\phi_{j}} \text {. }
$$

The axial position corresponding to highest measured activity of each isotope was chosen as the reference position, location $j$, in the above expressions for R.

\subsection{Experimental Approach}

The following nondestructive and destructive methods of PIE were designed relative to the goals of this investigation:

\subsubsection{Gamma Scan Method}

This nondestructive approach to PIE is a passive method and was carried out in two stages. In the first stage, the activity of gamma rays above a certain minimum energy ( $250 \mathrm{keV}$ ) and the gamma activity of one fission product $\left({ }^{137} \mathrm{Cs}\right.$ ) were monitored as the fuel rod axially traversed the scanning device. This "gross" scan was intended to detect any regions of high activity due to nonuniform fuel burnup or axial migration of fission products.

In the second part of this method, high resolution gamma spectra were recorded when the fuel rod was located so as to expose a well-aefined segment of an axial position to the detector. The relative amounts of different fission products were determined by the area of characteristic full energy gamma ray photopeaks. These fission products remaining at their formation site represented the extent of fission at that location and hence portrayed relative 
fuel burnup and power profiles. The relative concentration profiles of ${ }^{137} \mathrm{Cs}$, ${ }_{106} \mathrm{Ru}$, or ${ }^{95} \mathrm{Zr}$ and the relative activity ratio, $R_{134} / R_{137}$, were utilized in establishing time averaged neutron flux profiles at various axial positions.

The relative profiles of fuel burnup and power determined by the gamma scan method could be translated into time profiles by a measurement of absolute values along the fuel rod axis. For this purpose, transverse sections at two locations were obtained for each fuel rod and were analyzed radiochemically.

\subsubsection{Destructive Method}

Axial sections of fuel rods were dissolved and chemically analyzed. The radiochemical fractions were further analyzed by a mass spectrometer, and the fol. lowing data were obtained:

1. $\mathrm{U}$ and $\mathrm{Pu}$ isotopic abundances.

2. $237 \mathrm{~Np},{ }^{241} \mathrm{Am}$, and $243 \mathrm{Am}$ amounts .

3. Atomic ratio $148 \mathrm{Nd} / 238 \mathrm{U}$.

Isotopic abundances of $\mathrm{U}$ and $\mathrm{Pu}$ in the irradiated fuel can be utilized in the calculation of their respective depletions when the atomic composition of the fuet prior to irradiation is known.

The identifiable formation modes of $241 \mathrm{Am}$ and $243 \mathrm{Am}$ are the $(n, \gamma)$ reactions. $237 \mathrm{~Np}$, on the other hand, is formed predominantly by $B$ decay of $237 \mathrm{U}$ formed by successive capture of two neutrons by $235 \mathrm{U}$ or the nuclear reaction ${ }^{238} \cup(n, 2 n)^{237} \mathrm{U}$. The modes of formation of these nucilides depend uni the local neutron field. Their amounts, therefore, provide a means of evalualing neutron fluences.

The observed quantity of the shielded nuclide ${ }^{148} \mathrm{Nd}$ is a measure of total fissions at any location in the fuel, and the ratio $148 \mathrm{Nd} / 230 \mathrm{U}$ can be used to determine the extent of fission.

The results of the destructive method can be compared with similar data from the gamma scan method. Since the relative values of fuel burnup and neutron flux were known for positions of the rods that were destructively analyzed, average absolute values for the unit on the relative scale can be calculated, and the relative neutron flux values translated into absolute values. 


\section{EXPERIMENTAL DETAILS}

\subsection{Gamma Scan Method}

The experimental setup used consisted of positioning a fuel rod and viewing it through a double slit $1-m$ ( $240-i n$.$) collimator with a stationary Ge(Li) detec-$ tor positioned outside the hot cell. As the rod moved vertically, the extent of its travel was indicated by a calibrated odometer and the gamma detector was exposed to a small segment of the rod.

The collimator slits were set at $1.0 \mathrm{~mm}$ (primary) and $\sim 1.5 \mathrm{~mm}$ (scraper), respectively. A Ge(Li) detector with $\sim 2 \mathrm{keV}$ resolution at $1332 \mathrm{keV}$ and $7 \%$ detection efficiency was employed for gamma detection and the detector signals were processed by ORTEC modular electronics.

Continuous gamma scans of gross gamma and ${ }^{137} \mathrm{Cs}$ activities were recorded with a dual-pen strip chart recorder. ${ }^{95} \mathrm{Zr}$ gamma activitiy was also recorded in one pair of rods in which the isotope was detected.

Gamma spectra were recorded for 1000 seconds (1ive time) at 10 equally spaced axial positions of each rod. These spectra were stored, analyzed, and the nuclides identified with a Nuclear Data 6620 system. The spectral analysis by the system was based on a proprietary computer code that determined the areas of full energy photopeaks to identify specific isotopes.

\subsection{Rod Scctioning Operations}

General Atomic selected the axial locations of the burnup samples based on previous operating history. Samples $2.5-\mathrm{cm}$ ( $1-i n$.$) long were taken at 75$ and $80 \mathrm{~cm}$ ( 30 to 32 in.) and 243 and $248 \mathrm{~cm}$ (97 to 99 in.) from the bottom of the fuel rods for radiochemical analyses. Prior to sectioning, a detailed sample plan and specimen identification system were prepared for the rods. The rod sectioning diagrams are shown in Figures 1 and 2 . The locations of the samples and waste sections were measured using a Lufkin rule graduated in 1/16 inch. Each rod was sectioned using a modified tubing cutter. Individual samples and waste sections were stored in marked containers. The $0.25-\mathrm{cm}$ 
(0.1-in.) thick wafers needed for analys is were subsequently cut from the 1 in. segments. Exact locations for each sample are shown in Table 1. To insure that a complete sample cross section was obtained for burnup analysis, the samples were impregnated with a mixture of acetone and Duco cement. .Each sample was placed on a Buehler Isomet saw, measured and cut. A $0.25-\mathrm{cm}(0.1-\mathrm{in}$.) thick wafer from each sample was placed in a marked vial to maintain identification.

\subsection{Destructive Method}

Each sample of fuel submitted for destructive burnup analys is consisted of a fuel rod slice including fuel approximately 3-5 mm thick. This sample was dissolved in a dilute aqua regia solution made from a 12:3:10 ratio of $\mathrm{HNO}_{3}, \mathrm{HCl}$, and water, respectively. A portion of the dissolved mixture was diluted with $0.1 \mathrm{~N} \mathrm{HCl}$ and an aliquot of this tinal solution was used for analysis.

A spike containing known amounts of $233 \mathrm{U}, 244 \mathrm{Pu}$, and $250 \mathrm{Nd}$ was added to the aliquot of dissolved fuel. An unspiked fuel sample was also run in parallel to the spiked portion. The separation of $\mathrm{U}, \mathrm{Pu}$, and $\mathrm{Nd}$ used two sequential ion exchange columns operated at room temperature. The sample was fumed with $\mathrm{HF}$ and $\mathrm{HClO}_{4}$ to convert the $\mathrm{U}$ and $\mathrm{Pu}$ to the VI oxidation state. The sample was transferred to the first AGMP-1 anion exchange column in $12 \mathrm{~N} \mathrm{HCI}$. The effluent from this column containing $N d$, other fission products, and Am were converted to the nitrate form. The Pu was eluted from the first column with an $\mathrm{HI}-\mathrm{HCl}$ mixture and $\mathrm{U}$ was removed with $0.1 \mathrm{~N} \mathrm{HCl}$. The fission products and Nd were loaded onto a second anton exchange columin and Nd wds isolated by chromatographic elution with a mixture of $\mathrm{HNO}_{3}-\mathrm{CH}_{3} \mathrm{OH}$.

The U. $\mathrm{Pu}$, and $\mathrm{Nd}$ fractions were then analyzed by mass spectroscopy to determine the isotopic content of each fraction and the chemical yield provided by the spike. These data were used to calculate the nuclear burnup. 
Table 1. Identification and Location of Samples for Burnup Analys is

\begin{tabular}{|c|c|c|c|}
\hline \multirow[b]{2}{*}{ Rod No. } & \multirow[b]{2}{*}{ Sample } & \multicolumn{2}{|c|}{ Axial location (a } \\
\hline & & $\mathrm{cm}$ & Inches \\
\hline UN 097 & A & 250.19 & 98.5 \\
\hline UN: 097 & B & .77 .47 & 30.5 \\
\hline UN 098 & A & 250.19 & 98.5 \\
\hline UN 098 & B & .77 .47 & 30.5 \\
\hline UN 099 & A & 247.65 & 97.5 \\
\hline UN 099 & B & 80.01 & 31.5 \\
\hline UN 100 & A & 247.65 & 97.5 \\
\hline UN 100 & B & 80.01 & 31.5 \\
\hline UN 101 & A & 247.65 & 97.5 \\
\hline UN 101 & B & 80.01 & 31.5 \\
\hline UN 102 & $A$ & 247.65 & 97.5 \\
\hline UN 102 & B & 80.01 & 31.5 . \\
\hline
\end{tabular}

(a) From bottom of fuei rod. 
Figure 1. Rod Sectioning Diagram for Dresden Rods UN 0.97 and UN 098

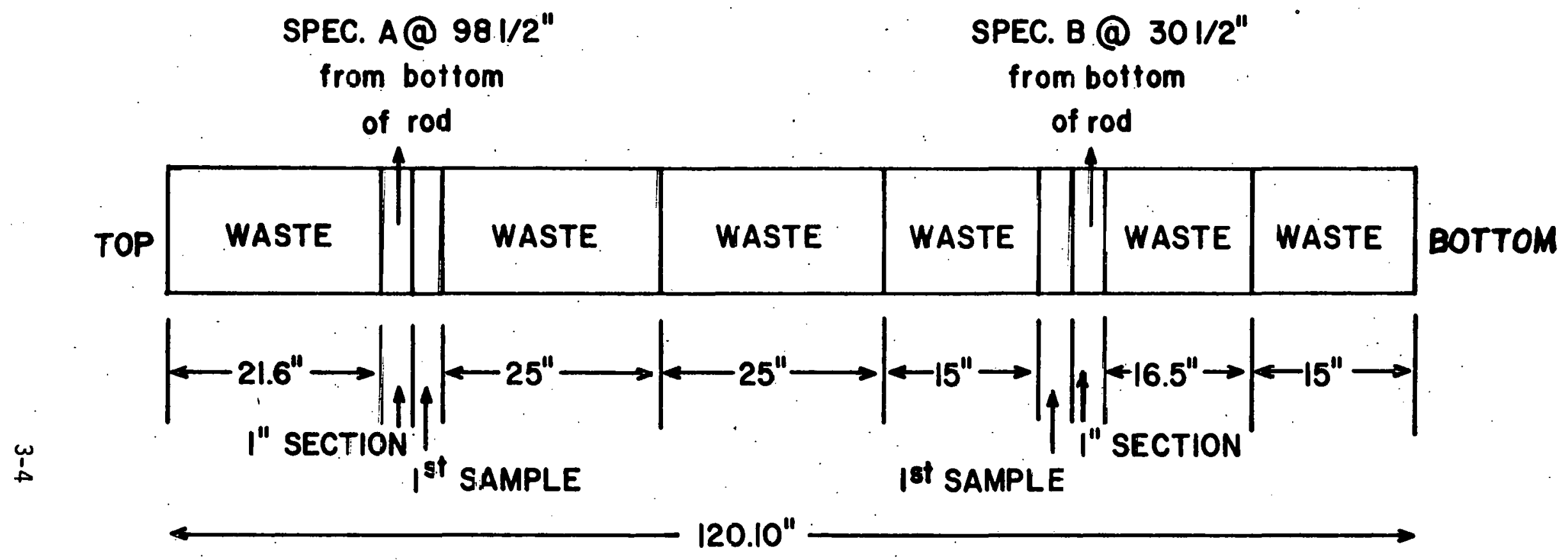


Figure 2. Rod Sectioning Diagram for Dresden Rods UN 099, UN 100, UN 101, and UN 102

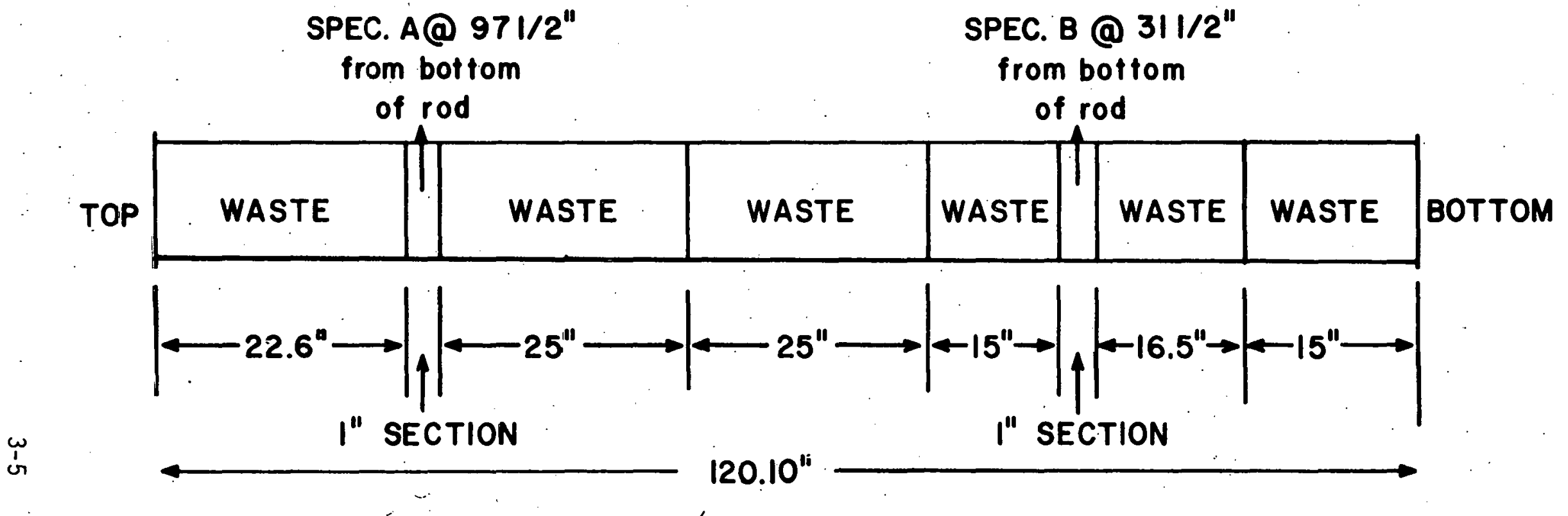




\section{RESULTS}

\subsection{Gamma Scan Method}

Gross gamma scans of radioactive isotopes with gamma energies up to about 2.0 $\mathrm{MeV}$ and the single channel selected gamma activity of ${ }^{137} \mathrm{Cs}$ for the six rods are shown in Figures 3 and 4 . Figure 5 contains the single-channel selected activity of ${ }^{95} \mathrm{Zr} /{ }^{95} \mathrm{Nb}$ for the pair of rods (UN 098 and UN 101) in which this activity was detected.

Tables 2 through 7 present the relative positional activities ( $R$ values) of characteristic gamma rays of isotopes ${ }^{137} \mathrm{Cs},{ }^{134} \mathrm{Cs}$, and ${ }^{106} \mathrm{Ru}$, along with $\mathrm{R}$ values for ${ }^{95} \mathrm{Zr}$ for rods in which this activity was detected. The axial positions where transverse sections were taken for radiochemical analysis are indicated by pointers. These R values; alșo shown in Figures 6 through 11, were computed by dividing the activity at each location by the highest observed activity. Since the decay corrections and attentuation factors for their growth during irradiation are identical for the same isotope regardless of its location in the fuel rod, the $R$ values represent the relative numbers of atoms of the isotope at various axial positions.

The irradiation and decay history of the fuel rods relative to the time of counting is shown schematically in Figure 12. Periods corresponding to six half-lives of the shorter lived isotopes ${ }^{106} \mathrm{Ru}$ and ${ }^{95} \mathrm{Zr}$ are also shown in Figure 12. The period of growth of the detected activity during irradiation was determined (Figure 12), assuming the activity of these isotopes could be detected only for six half-lives.

\subsection{Radfochemical Analyses}

The isotopic analys is of ion exchange separated uranium, plutonium, and neodymium fractions of fuel rod samples are given in Table 8 . The analyzed samples are also identified in Table 1. The number of atoms of each isotope is expressed relative to $10^{6}$ atoms of ${ }^{238} \mathrm{U}$ present in the fuel after irradiation. 
As explained earlier (see section 3.3), the amount of respective spike elements and their isotopic compositions were utilized in the calculations.

The number of a toms of $\mathrm{U}, \mathrm{PU}$, and $\mathrm{Nd}$ isotopes given in Table 8 is based on a mass spectroscopic analys is of the respective fractions from ion exchange separations. The number of ${ }^{241} \mathrm{Am}$ and ${ }^{237} \mathrm{~Np}$ atoms was evaluated by gamma counting aliquots of dissolved fuel samples. The intensities of 59.6 and $86.5 \mathrm{keV}$ gamma rays in gamma spectra recorded with a calibrated gamma detection system were used in the calculations. The gamma ray characteristic of ${ }^{24}{ }^{3} \mathrm{Am}(74.5 \mathrm{keV})$ was not identified in any of the gamma spectra recorded and analyzed. The minimum detectable intensity of this gamma ray with the detection system employed was $0.05 \mathrm{cps}$ and corresponds to about one atom of ${ }^{243} \mathrm{Am}$ for every $10^{6}$ atoms of $238 \mathrm{U}$ in the dissolved sample for which the relative number of atoms of other isotopes are represented in Table 8.

The burnup was calculated from changes in the uranium and plutonium content as well as the fission product content (Nd) as described in ASTM methods E-244, $E-267$, and E-321.

The destructive analysis of a fuel sample yielded burnup as fissions per initial atom of uranium and plutonium. This value can be converted to gigawatt days per metric ton by multiplying by 960 . The uncertainty in this conversion factor is $3 \%$. The uncertainty in the measured values is approximately $3.5 \%$. The overall error associated with the burnup expressed as liwd/mt is dusut 4.6\%.

The initial isotopic abundances used in the calculations were the specification values for these assemblies, i.e., natural uranium, $71.7 \% 239 \mathrm{Pu}, 20.6 \% 24 \mathrm{Pu}$, $6.4 \% 241 \mathrm{Pu}, 1.0 \% 242 \mathrm{Pu}$, and $0.3 \%{ }^{238} \mathrm{Pu}$. The capture-to-fission ratios for the fissile isotopes were the default values in the General Electric burnup computer code. 
Table 2. Relative Axial Concentrations of Fission Products in Fuel Rod UN 097

\begin{tabular}{|c|c|c|c|c|c|c|c|c|}
\hline $\begin{array}{l}\text { Axial } \\
\text { position(a) }\end{array}$ & $\begin{array}{l}\text { Isotope, } \\
\mathrm{E}_{\gamma} \text { (keV) }\end{array}$ & $\begin{array}{l}137 \mathrm{Cs} \\
661.5 \\
\end{array}$ & $\begin{array}{l}134 \mathrm{Cs} \\
795.8 \\
\end{array}$ & $\begin{array}{l}106 \mathrm{Ru} \\
621.8 \\
\end{array}$ & $\begin{array}{l}95 \mathrm{Zr} \\
756.0 \\
\end{array}$ & & & \\
\hline $\mathrm{cm}$ & Inches & $R_{137}$ & $R_{134}$ & $R_{106}$ & $R_{95}$ & $R_{134} / R_{137}$ & $R_{106} / R_{137}$ & $R_{95} / R_{137}$ \\
\hline 266.57 & 104.95 & 0.410 & 0.154 & 0.418 & & $0: 375$ & 1.019 & \\
\hline 250.57 & 98.65 & 0.590 & 0.362 & 0.591 & & 0.614 & 1.003 & \\
\hline 211.46 & 83.25 & 0.863 & 0.813 & 0.894 & & 0.942 & 1.036 & \\
\hline 182.75 & 71.95 & 0.928 & 0.909 & 1.000 & & 0.979 & 1.077 & \\
\hline 158.12 & 62.25 & 0.959 & 0.979 & 0.953 & & 1.022 & 0.994 & \\
\hline 131.70 & 51.85 & 0.974 & 0.980 & 0.998 & & 1.007 & 1.025 & \\
\hline 105.28 & 41.45 & 0.994 & 1.000 & 0.996 & & 1.006 & 1.002 & \\
\hline 66.42 & 26.15 & 1.000 & 0.966 & 0.982 & & 0.966 & 0.982 & \\
\hline $19.94^{\prime}$ & 7.85 & 0.706 & 0.463 & 0.672 & & 0.655 & 0.951 & \\
\hline 0.38 & 0.15 & 0.399 & 0.117 & 0.362 & & 0.293 & 0.908 & \\
\hline Maximum pe & $k$ area & 229,183 & $32,01.3$ & 6.552 & & & & \\
\hline
\end{tabular}

(a) From bottom of fuel stack. 
Table 3. Relative Axial Concentrations of Fission Products in Fuel Rod UN 102

\begin{tabular}{|c|c|c|c|c|c|c|c|c|}
\hline $\begin{array}{c}\text { Axial } \\
\text { position (a) }\end{array}$ & $\begin{array}{l}\text { Isotope, } \\
E_{Y} \text { (keV) }\end{array}$ & $\begin{array}{l}137 \mathrm{Cs} \\
661.6 \\
R\end{array}$ & $\begin{array}{l}134 \mathrm{Cs} \\
795.8 \\
R\end{array}$ & $\begin{array}{l}106 \mathrm{Ru} \\
621.8 \\
R\end{array}$ & $\begin{array}{l}{ }^{95} \mathrm{Zr} \\
\frac{756.0}{R}\end{array}$ & & & \\
\hline $\mathrm{cm}$ & Inches & $R_{137}$ & $R_{134}$ & $R_{106}$ & $\underline{R_{95}}$ & $R_{134} / R_{1 \lesssim 7}$ & $R_{106} / R_{137}$ & $R_{95} / R_{137}$ \\
\hline 267.46 & 105.30 & 0.456 & 0.183 & 0.437 & & 0.401 & 0.959 & \\
\hline 252.98 & 99.60 & 0.622 & 0.400 & 0.578 & & 0.644 & 0.930 & \\
\hline 213.36 & 84.00 & 0.924 & 0.894 & 0.838 & & 0.968 & 0.907 & \\
\hline 183.64 & 72.3 & 0.966 & 0.968 & 0.881 & & 1.003 & 0.912 & \\
\hline 157.99 & 62.2 & 0.991 & 0.980 & 0.904 & & 0.990 & 0.912 & \\
\hline 131.83 & 51.9 & 0.998 & 1.000 & 1.000 & & 1.002 & 1.002 & \\
\hline 106.68 & 42.00 & 1.000 & 0.951 & 0.891 & & 0.951 & $0.891^{\circ}$ & \\
\hline 66.80 & 26.3 & 0.971 & 0.875 & 0.889 & & 0.900 & 0.916 & \\
\hline 19.81 & 7.80 & 0.671 & 0.408 & 0.682 & & 0.609 & 1.016 & \\
\hline 0.51 & 0.20 & 0.382 & 0.105 & 0.369 & & 0.274 & 0.964 & \\
\hline Maximum peak & area & 237,462 & 35,486 & 7,338 & & & & \\
\hline
\end{tabular}


Table 4. Relative Axial Concentrations of Fission Products in Fuel Rod UN 098

\begin{tabular}{|c|c|c|c|c|c|c|c|c|}
\hline $\begin{array}{l}\text { Axial } \\
\text { position }\end{array}$ & $\begin{array}{l}\text { Isotope, } \\
\mathrm{E}_{\mathrm{Y}}(\mathrm{keV})\end{array}$ & $\begin{array}{l}137 \mathrm{Cs} \\
661.6 \\
\end{array}$ & $\begin{array}{l}134 \mathrm{Cs} \\
795.8 \\
\end{array}$ & $\begin{array}{l}106 \mathrm{Ru} \\
621.8 \\
\end{array}$ & $\begin{array}{l}95 \mathrm{Zr} \\
756.0 \\
\end{array}$ & & & \\
\hline $\mathrm{cm}$ & Inches & $R_{137}$ & $R_{134}$ & $R_{106}$ & $R_{95}$ & $R_{134} / R_{137}$ & $R_{106} / R_{137}$ & $R_{95} / R_{137}$ \\
\hline 267.97 & 105.50 & 0.478 & 0.192 & 0.433 & 0.431 & 0.402 & 0.906 & 0.902 \\
\hline 253.75 & 99.90 & 0.631 & 0.399 & 0.649 & 0.632 & 0.632 & 1.028 & 1.001 \\
\hline 159.00 & 62.60 & 0.982 & 0.984 & 0.983 & 0.855 & 1.002 & 1.001 & 0.871 \\
\hline 132.59 & 52.20 & $1.0 \mathrm{CO}$ & 1.000 & 1.000 & 0.909 & 1.000 & 1.000 & 0.909 \\
\hline 106.43 & 41.90 & 0.994 & 0.961 & 0.977 & 0.969 & 0.966 & 0.983 & 0.975 \\
\hline 67.56 & 26.60 & 0.964 & 0.882 & 0.920 & 1.000 & 0.915 & 0.955 & 1.038 \\
\hline
\end{tabular}

(a) From bottom of fuel stack. 
Table 5. Relative Axial Concentrations of Fission Products in Fuel Rod UN 101

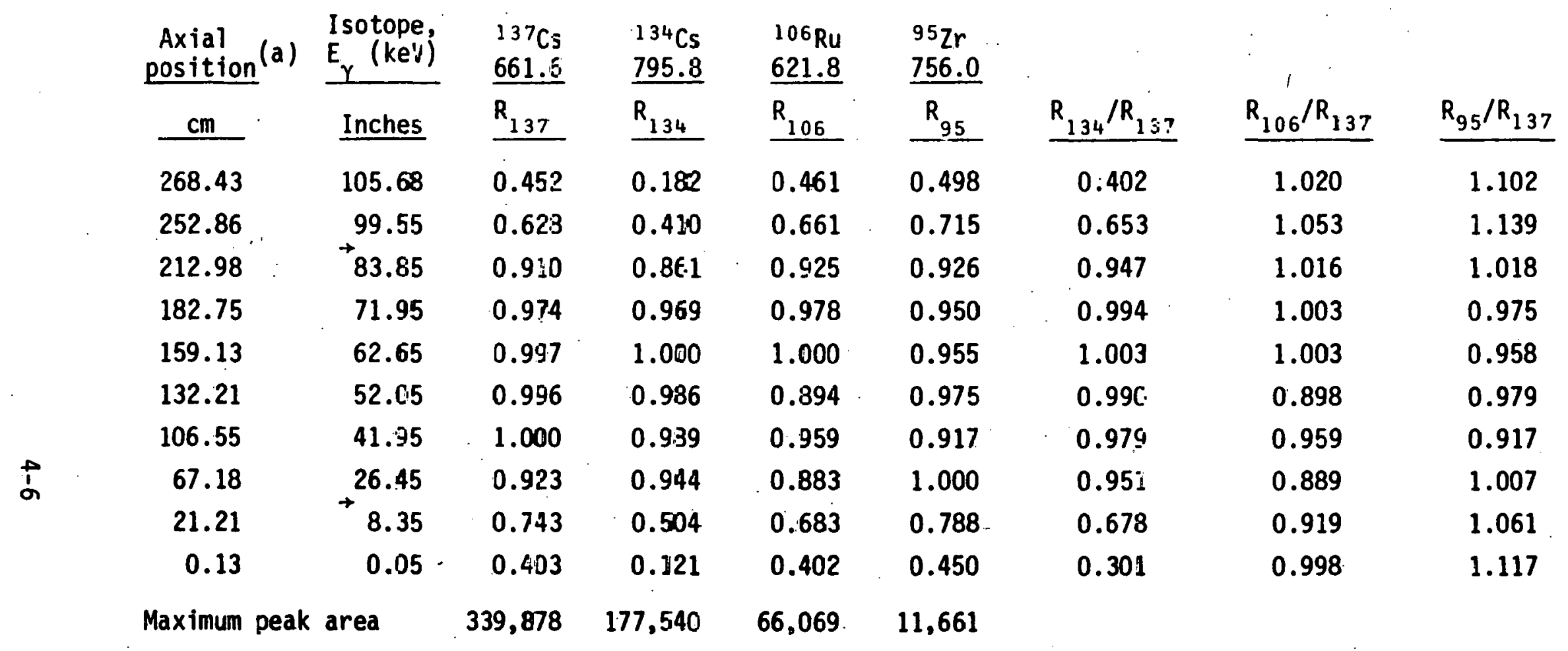

\footnotetext{
(a) From bottom of fuel stack.
} 
Table 6. Relative Axial Concentrations of Fission Products in Fuel Rod UN 099

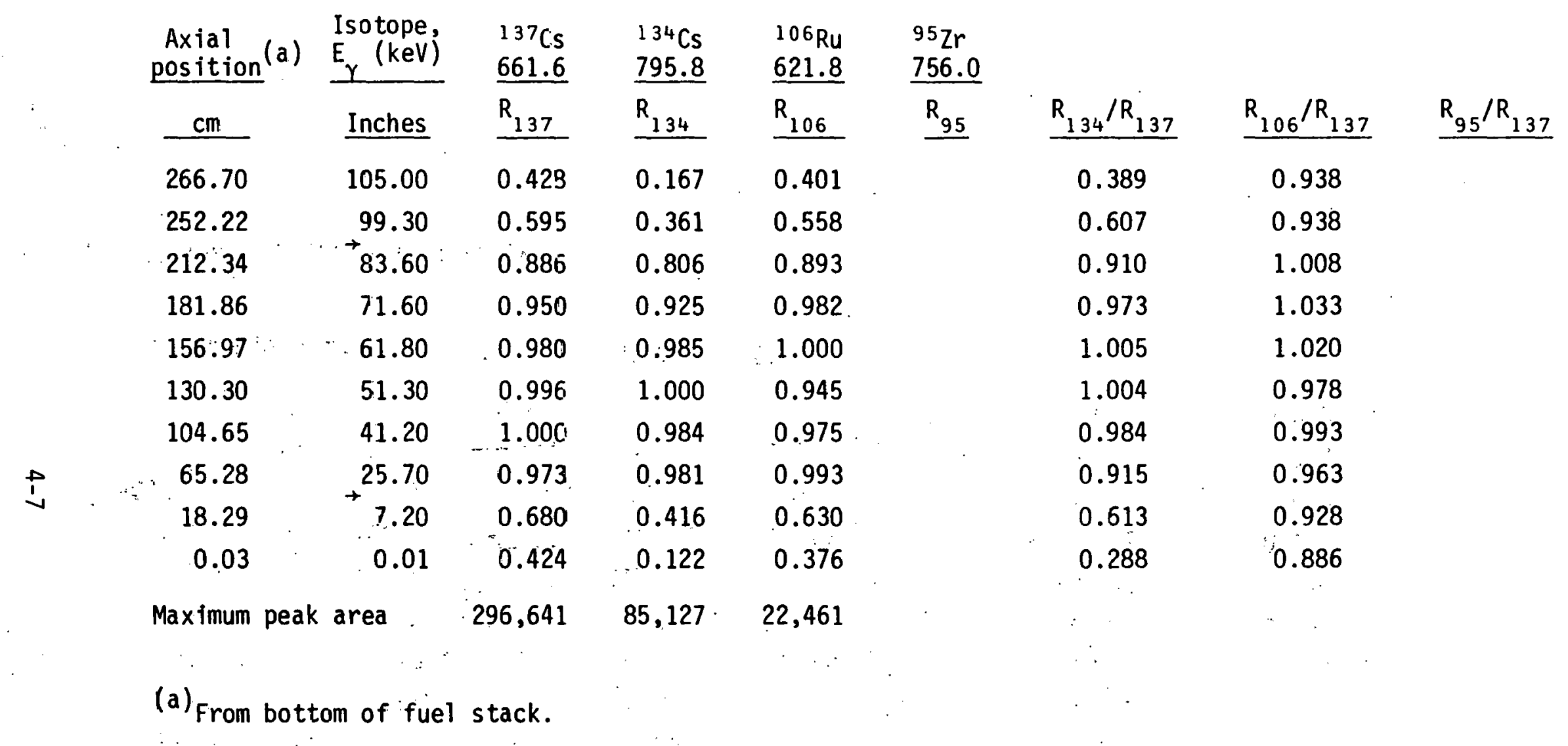


Table 7. Relative Axial Concentrations of Fission Products in Fuel Rod UN 100

\begin{tabular}{|c|c|c|c|c|c|c|c|c|}
\hline $\begin{array}{l}\text { Axial } \\
\text { position }\end{array}$ & $\begin{array}{l}\text { Isotope, } \\
\mathrm{E}_{\gamma} \quad(\mathrm{keV})\end{array}$ & $\begin{array}{l}1 \leqslant 7 \mathrm{Cs} \\
661.6 \\
\end{array}$ & $\begin{array}{l}134 \mathrm{Cs} \\
795.8 \\
\end{array}$ & $\begin{array}{l}106 \mathrm{Ru} \\
621.8 \\
\end{array}$ & $\begin{array}{l}95 \mathrm{Zr} \\
756.0 \\
\end{array}$ & & & \\
\hline $\mathrm{cm}$ & Inches & $R_{137}$ & $R_{134}$ & $R_{106}$ & $R_{95}$ & $R_{134^{\prime}}{ }^{\prime} R_{137}$ & $R_{106} / R_{137}$ & $R_{95} / R_{137}$ \\
\hline 267.08 & 105.15 & $0.43 \pi^{\circ}$ & 0.172 & 0.454 & & $0: 394$ & 1.038 & \\
\hline 252.86 & 99.55 & 0.575 & 0.335 & 0.564 & & 0.584 & 0.980 & \\
\hline 212.22 & $\Rightarrow 83.55$ & 0.846 & 0.816 & 0.903 & & 0.965 & 1.068 & \\
\hline 183.01 & $72: 05$ & 0.912 & 0.940 & 0.973 & & 1.032 & 1.068 & \\
\hline 158.37 & 62.35 & 0.960 & $1.0 \mathrm{CO}$ & 0.953 & & 1.041 & 0.992 & \\
\hline 131.95 & 51.95 & 0.956 & 0.998 & 1.000 & & 1.044 & 1.046 & \\
\hline 105.54 & 41.55 & 1.000 & $0.9: 3$ & 0.979 & & 0.913 & 0.979 & \\
\hline 66.42 & 26.15 & D.949 & 0.820 & 0.914 & & 0.863 & 0.963 & \\
\hline 19.69 & 7.75 & 0.688 & 0.420 & 0.668 & & 0.610 . & 0.971 & \\
\hline 0.13 & 0.05 & 0.395 & 0.106 & 0.374 & & 0.269 & 0.948 & \\
\hline Maximum peal & Irea & $2 \varepsilon 8, C 9 \subseteq$ & 80,697 & 20,135 & & & & \\
\hline
\end{tabular}

(a) From bottom of fuel stack. 
Table 8. Atomic Composition of Mixed 0xide Fuel Samples

\begin{tabular}{|c|c|c|c|c|c|c|c|c|c|c|c|c|}
\hline & & & & & & & Sample & & & & & \\
\hline & Isotope & $97-B$ & $98-A$ & 98-B & $99-A$ & 99-B & $100-A$ & 100-B & $101-A$ & $101-B$ & 102-A & $102-B$ \\
\hline & $U-238$ & $1.00 E+06$ & $1.00 E+06$ & $1.00 E+06$ & $1.00 E+06$ & $1.0 n E+06$ & $1.00 E+06$ & $1: 00 E+06$ & $1.00 \mathrm{E}+06$ & $1.00 E+06$ & $1.00 E+06$ & $1.00 E+06$ \\
\hline & $U-236$ & 635 & 696 & 894 & 556 & 755 & 408 & 452 & 536 & 718 & 468 & 641 \\
\hline & $U-235$ & 3841 & 3821 & $226 \varepsilon$ & 4454 & 3038 & 5175 & 2750 & 4596 & 3197 & 4881 & 3844 \\
\hline & $U-\bar{c} 34$ & 65 & $81^{\circ}$ & 108 & 68 & 71 & 44 & 42 & 52 & 49 & 48 & 33 \\
\hline & $P u-\check{c} 42$ & 842 & 855 & $135 E$ & 695 & 1082 & 557 & 616 & 650 & 1052 & 607 & 841 \\
\hline & $P u-c 41$ & 1379 & 1712 & $157 \varepsilon$ & 1566 & 1508 & 1347 & 1002 & 1494 & 1544 & 1422 & 1376 \\
\hline & $P u-\varepsilon 40$ & 4895 & 4910 & 4595 & 4762 & 4908 & 4783 & 3614 & 4817 & 5016 & 4841 & 4912 \\
\hline & Pu-239 & $5442^{\circ}$ & 6164 & 3959 & 7108 & 4672 & 8245 & 3990 & 7367 & 4992 & 8040 & 5478 \\
\hline & $\mathrm{Pu} u-\hat{c} 38$ & 190 & 306 & $33 \varepsilon$ & 230 & 265 & 165 & 138 & 217 & 313 & 177 & 20 \\
\hline & $N d-150$ & 229 & 299 & 287 & 164 & 378 & 120 & 137 & 214 & 249 & 145 & 255 \\
\hline & $N d-148$ & 414 & 525 & 505 & 278 & 522 & 205 & 244 & 278 & 417 & 240 & 404 \\
\hline & $N d-146$ & 676 & 900 & 869 & 456 & 950 & 339 & 402 & 479 & 704 & 408 & 655 \\
\hline & $N d-145$ & 734 & 884 & 865 & 479 & 788 & 367 & 435 & 391 & 714 & 413 & 674 \\
\hline & $N d-144$ & 1171 & 1441 & 1554 & 740 & 1591 & 547 & 692 & 740 & 1207 & 654 & 1102 \\
\hline & $N d-143$ & 951 & 1157 & 996 & 645 & 1010 & 506 & 656 & 633 & 894 & 566 & 880 \\
\hline & $N d-142$ & 39 & 277 & 32 & 58 & 488 & 43 & 122 & 365 & 121 & 121 & 141 \\
\hline & Am-24l & 625 & 129 & 78 & 752 & 966 & .976 & 773 & 1034 & 327 & 1282 & 172 \\
\hline & $\mathrm{Np}-237$ & $2.00 E+06$ & $9.16 E+05$ & $2.36 \mathrm{E}+06$ & $2.99 E+06$ & $8.68 E+05$ & $2.39 E+06$ & $2.56 E+06$ & $3.27 E+06$ & $2.66 E+06$ & $3.07 E+06$ & $7.81 E+05$ \\
\hline
\end{tabular}



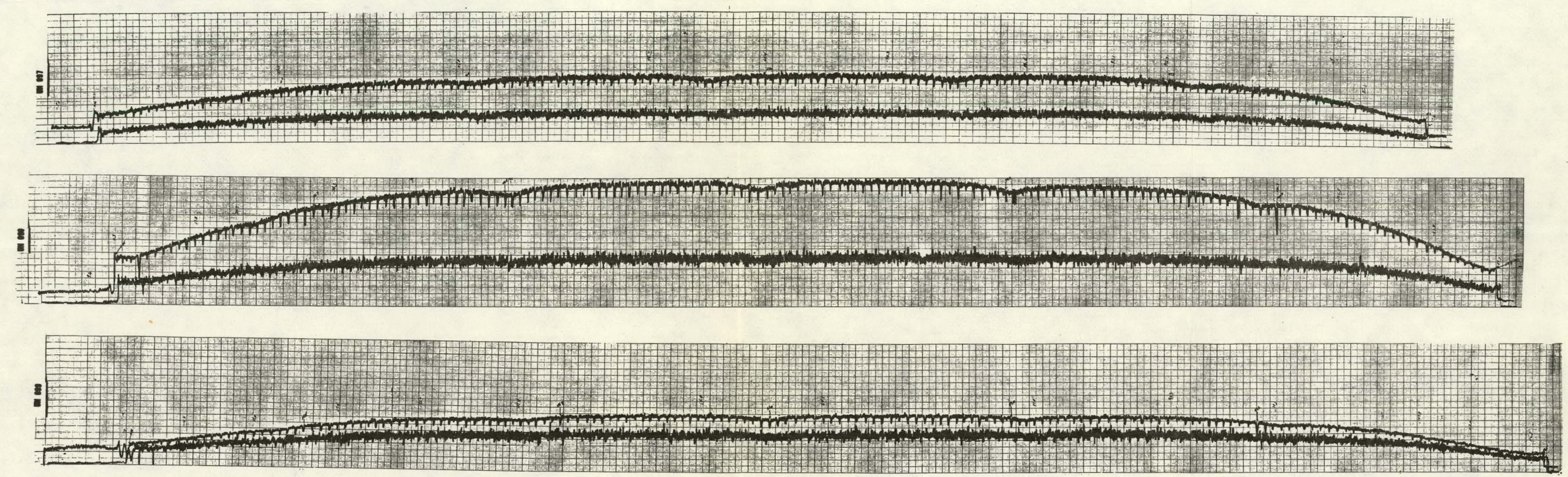


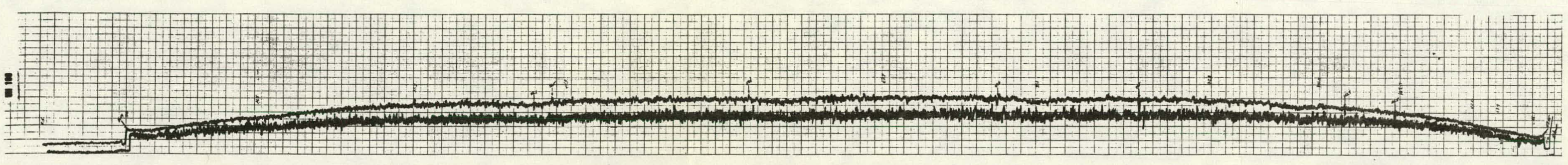

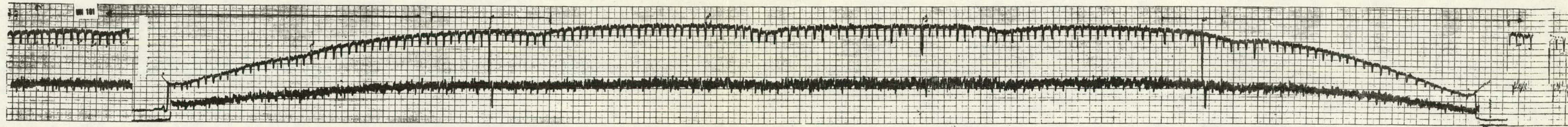

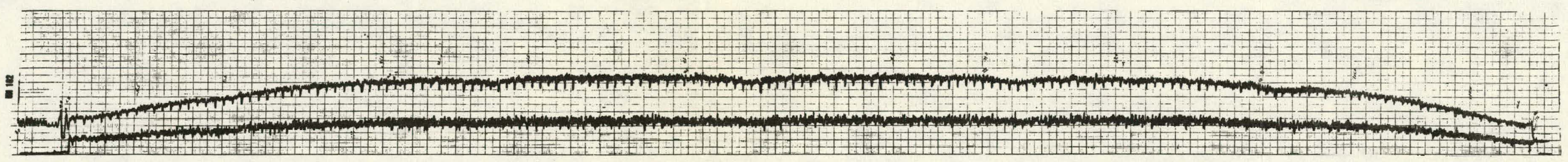


Figure 5. Scans of ${ }^{95} \mathrm{Zr}$ Activity in 101

: j um

4-12

Babcock \& Wilcox 
Figure 6. Relative Activities of $137 \mathrm{Cs},{ }^{106} \mathrm{Ru}$ and Activity Ratio ${ }^{138} \mathrm{Cs} /{ }^{137} \mathrm{Cs}$ for Rod UN 097

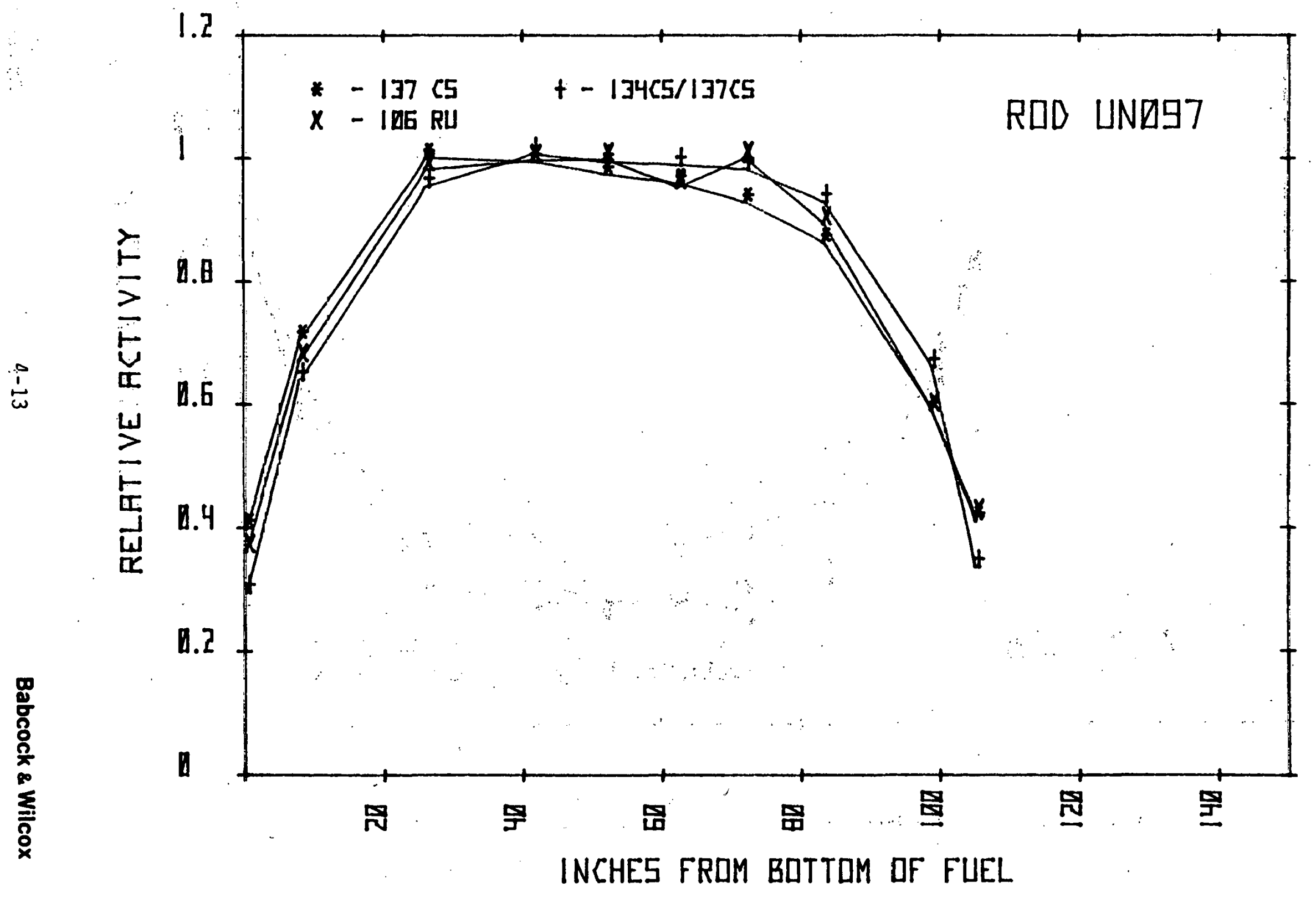


Figure 7. Relative Activities of ${ }^{137} \mathrm{Cs},{ }^{106} \mathrm{Ru}$ and Activity Ratio ${ }^{134} \mathrm{Cs} /{ }^{137} \mathrm{Cs}$ for Rod UN 102

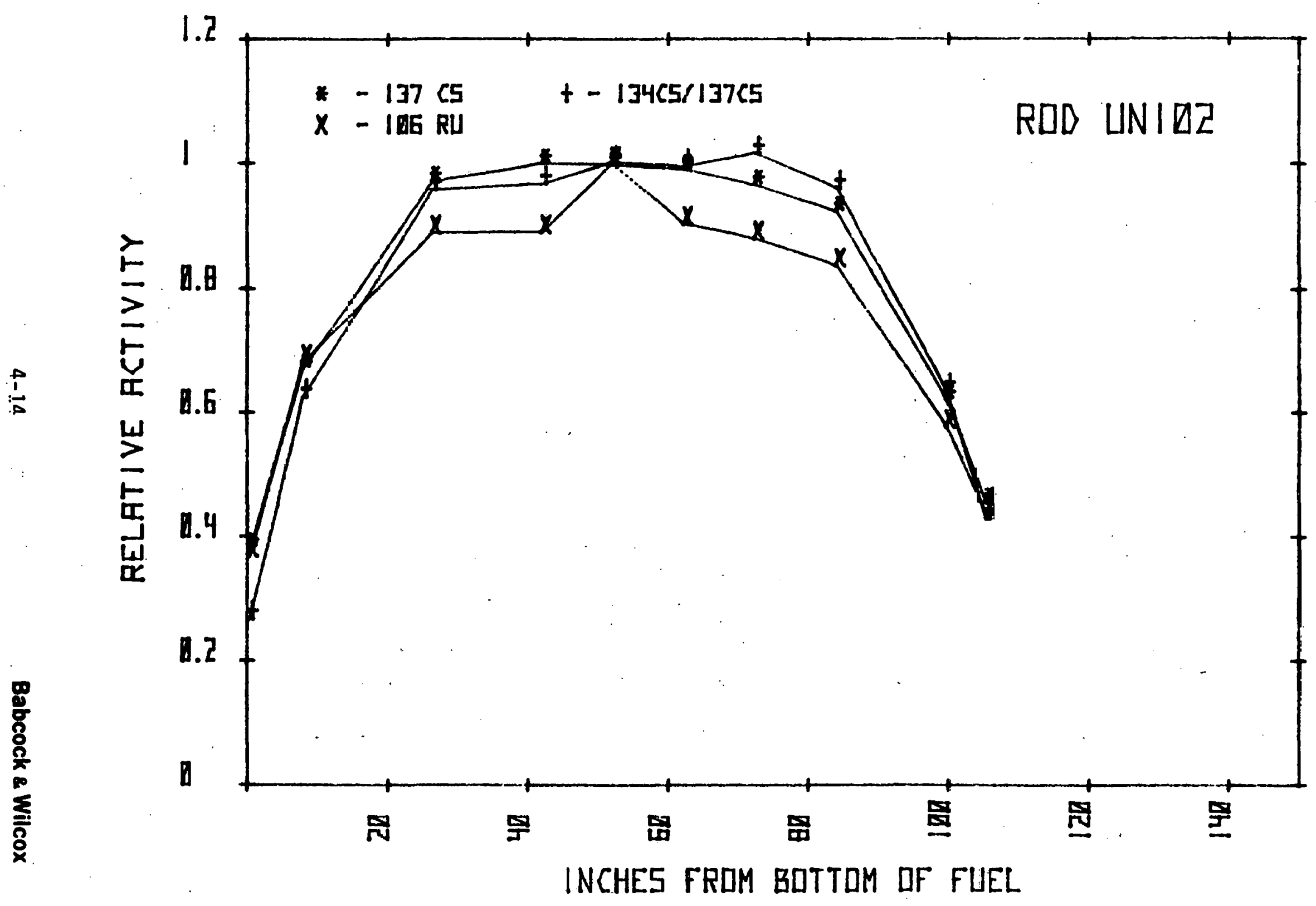


Figure 8. Relative Activities of ${ }^{137} \mathrm{Cs},{ }^{106} \mathrm{Ru}$ and Activity Ratio $1{ }^{44} \mathrm{Cs} /{ }^{137} \mathrm{Cs}$ for Rod UN 098

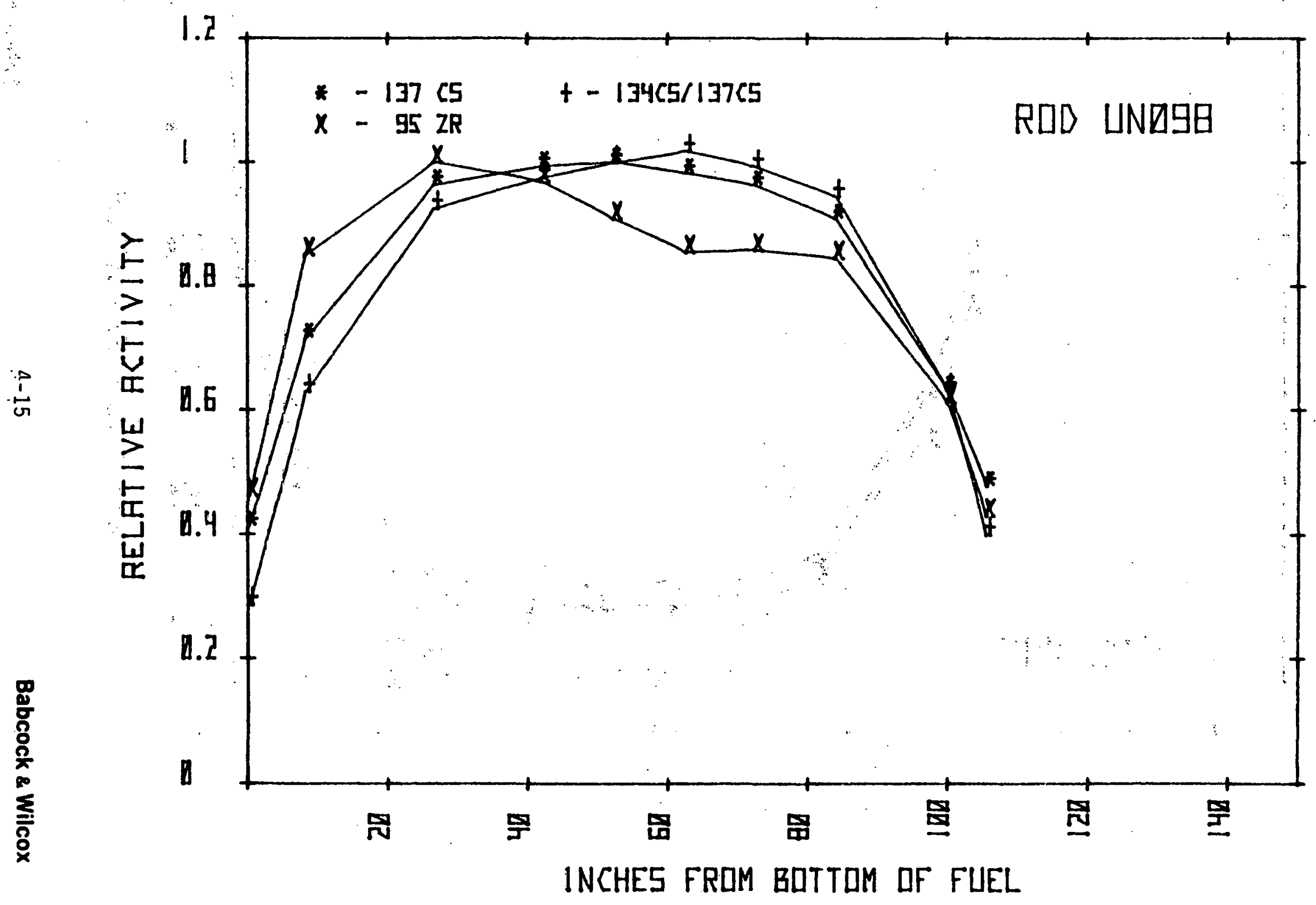


Figure 9. Relative Activities of $137 \mathrm{Cs}, 106 \mathrm{Ru}$ and Activity Ratio ${ }^{134} \mathrm{Cs} / 13.7 \mathrm{Cs}$ for Rod UN 101

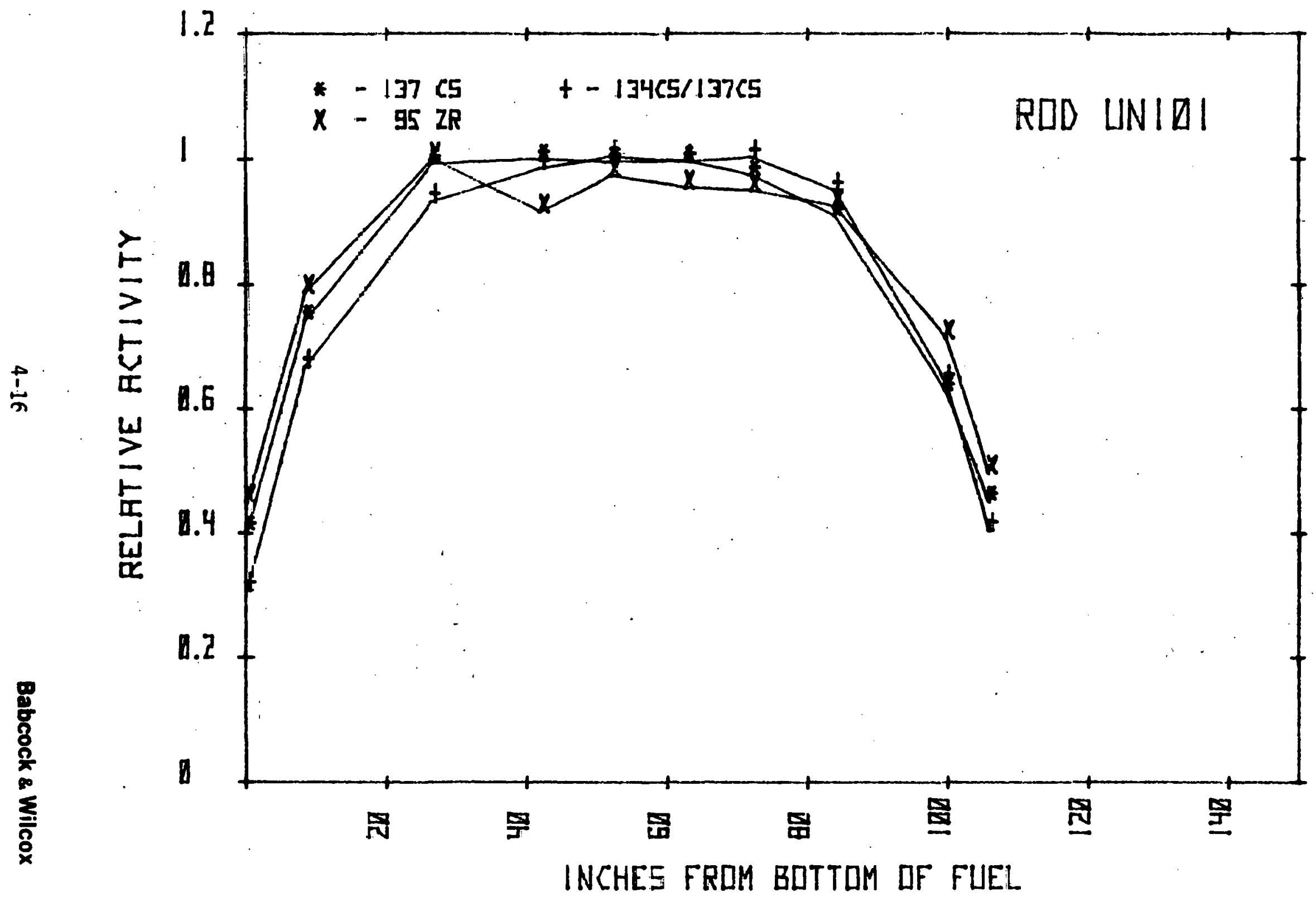


Figure 10: Relative Activities of ${ }^{137} \mathrm{Cs},{ }^{106} \mathrm{Ru}$ and Activity Ratio ${ }^{134} \mathrm{Cs} / 1{ }^{37} \mathrm{Cs}$ for Rod UN 099

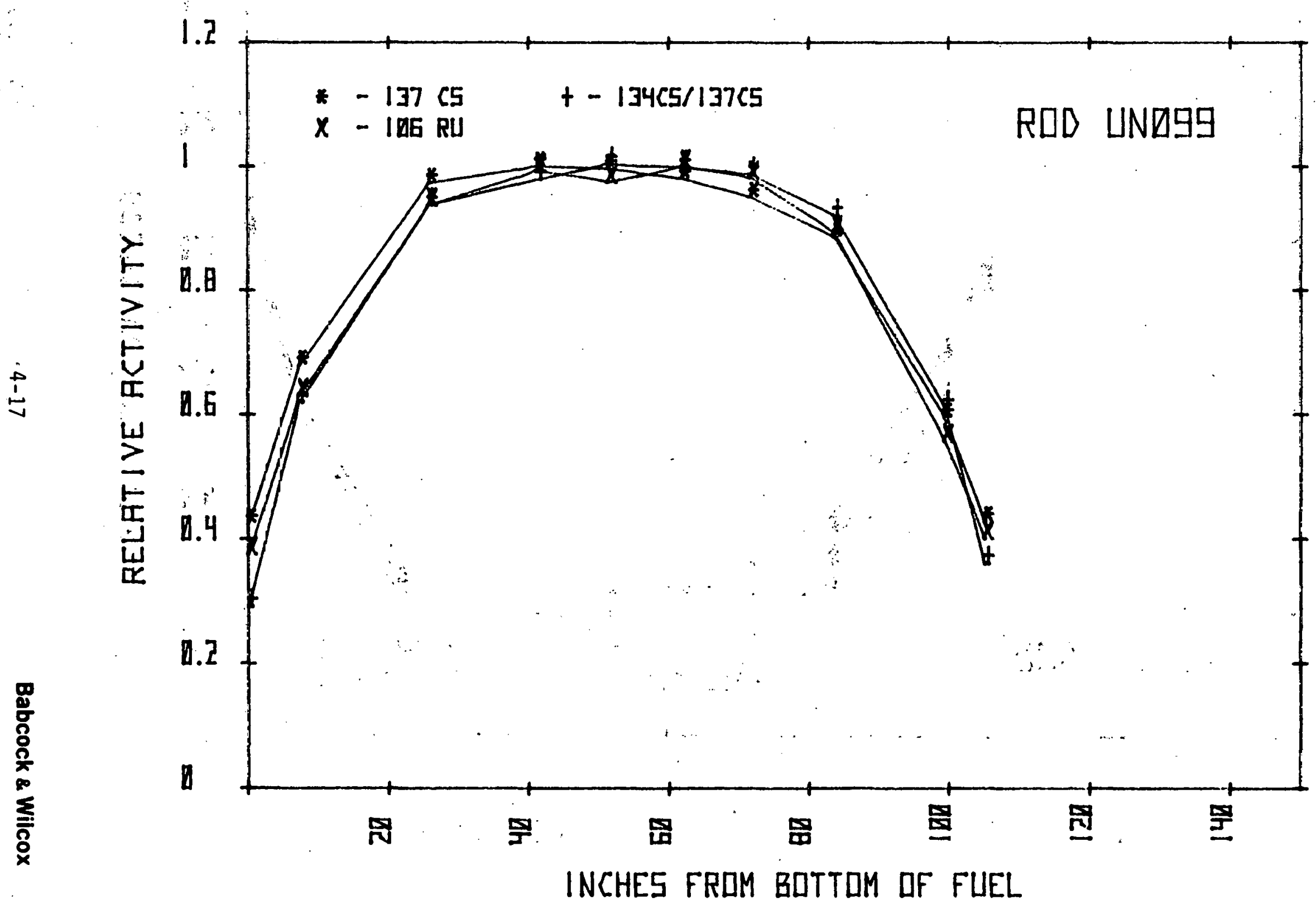


Fiçure 11. Relative Activities of ${ }^{137} \mathrm{Cs},{ }^{106} \mathrm{Ru}$ and Activity Ratio ${ }^{134} \mathrm{Cs} /{ }^{137} \mathrm{Cs}$ for Rod UN 100

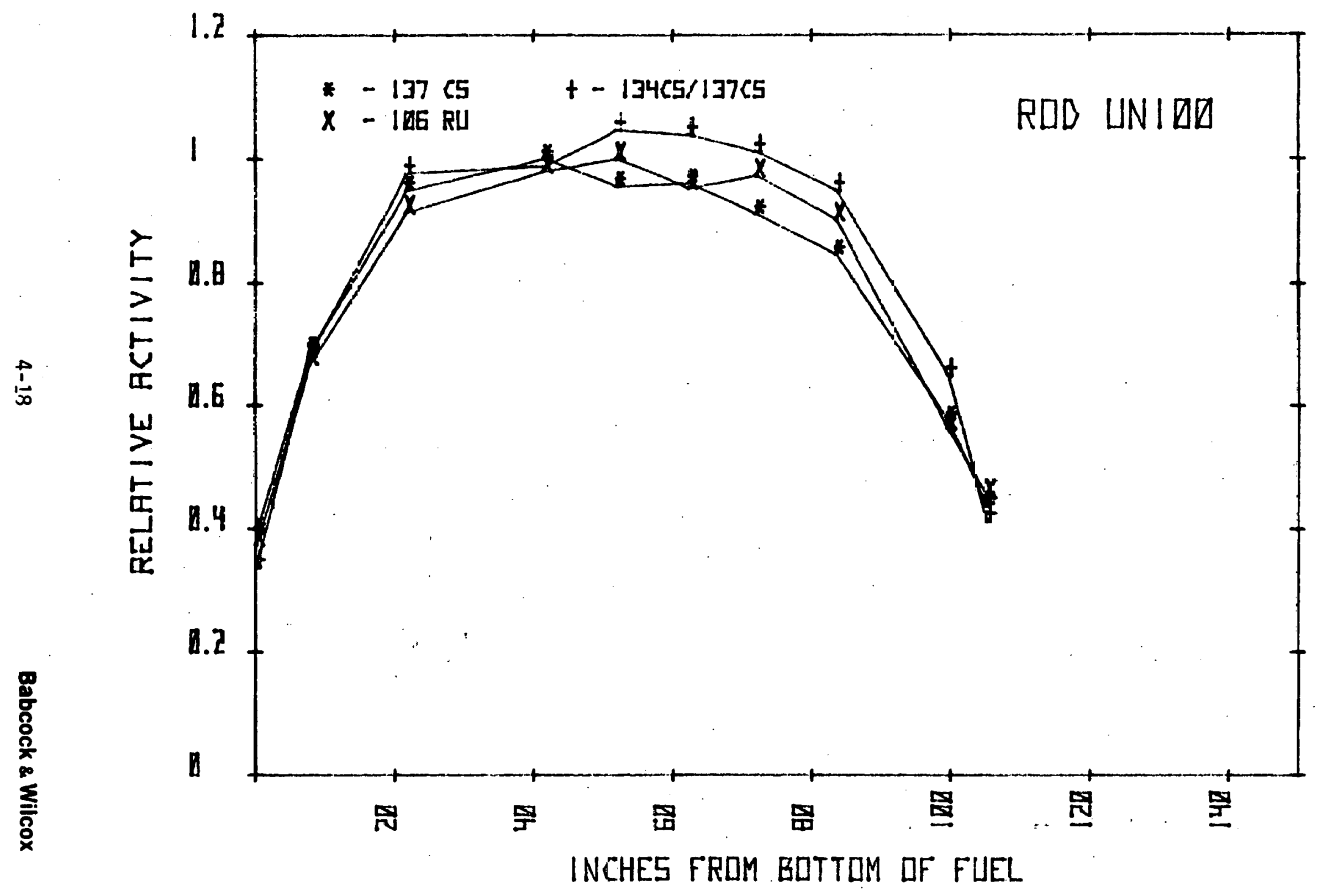


Figure 12. Irradiation Histories and Growth Periods of Short-Lived Isotopes Detected

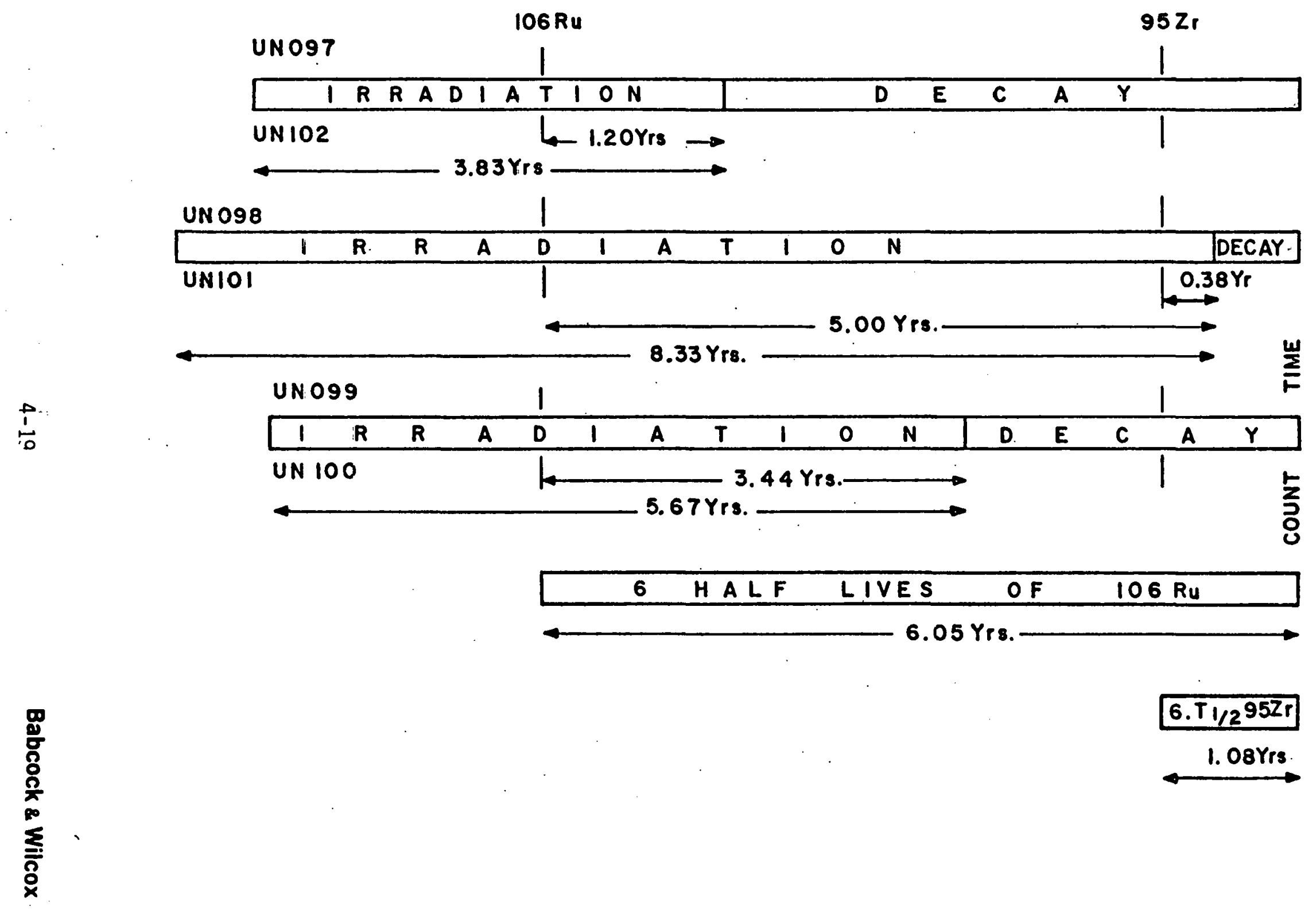




\section{DISCUSSION}

\section{Gamma Scan Method}

The gross gamma scans did not indicate any specific regions of high activity. This observation allows us to rule out axial migration of fission products since any such occurrence is expected to show up as localized activity; particularly at the interpellet gaps.

The interpellet gaps in the fuel rods are indicated by a decrease in gamma activity seen in Figures 3 through 5. From the regular spacing. of the inverted spikes, it can be concluded that there were no major changes in the physical form of the pellets due to irradiation. The only exceptions observed were the two wider than usual interpellet gaps in the scan of rod UN 101. It can be seen from the repeat scans of the same regions on the following day (shown at the ends of the scan in Figure 4), that one of the wider gaps at the upper end of the rod disappeared. This was attributed to a settling of fuel pellets due to the handling of the rods. This was further supported by a slight change in the positions of interpellet gaps in the later scan of the same region. The reproducible wider gap at the bottom of the rod was not considered serious enough to warrant a. detailed investigation. This was further supported by the observation of identical interpellet gaps in the original and repeat gamma scans. It was, therefore, concluded that this wider gap originated at the time the fuel rod was assembled.

The isotopes for which relative activity data, $R$ values, are given in Tables 2 through 7:, were chosen for their mode of formation and half-lives. ${ }^{137} \mathrm{Cs}$, ${ }^{106} \mathrm{Ru}$, and ${ }^{95} \mathrm{Zr}$ being primary products of fission, their $\mathrm{R}$ values represent fuel burnup profiles during part or al. of the irradiation period. The activity of $1{ }^{37} \mathrm{Cs}$ detected would be from fuel burnup during the entire irradiation because of its long half-life. The $R$ values of ${ }^{106} \mathrm{Ru}$ and ${ }^{95} \mathrm{Zr}$ portray relative fuel burnup profiles during a part of the irradiation (see Figure 12) with ${ }^{95} \mathrm{Zr}$ revealing the relative profile of late-in-life fuel burnup. 
The $R$ values of ${ }^{134} \mathrm{Cs}$ and the $R$ value ratio; $R_{134} / R_{137}$, represent the square of neutron flux and the neutron flux, respectively, averaged over the entire irradiation period because of the fact that all. ${ }^{134} \mathrm{Cs}$ formed during that period was counted.

A consideration of Table 5, in light of the above general conclusions, reveals the fuel burnup profiles of fuel rod UN 101 during various stages of irradiation. The maximum fuel burnup for the entire irradiation of 8.33 years occurred, based on the $R_{137}$ value, at about $106 \mathrm{~cm}$ from the bottom of the fuel stack. The values of $R_{106}$ indicate that during the later 5-year period, maximum fuel burnup rate took place at about $159 \mathrm{~cm}$ while late-in-life $R_{95}$ values show that the fuel burnup rate is higher at the ends of the rod. This is also reflected in the $R$ value ratios, $R_{106} / R_{137}$, where the values greater than unity represent increased fuel burnup rate at later periods of irradiation compared to the average burnup during the entire irradiation.

The time averaged neutron flux, on the basis of the ratio $R_{134} / R_{137}$, and its squared value represented by $R_{134}$, show maximum values at the same axial position of about $159 \mathrm{~cm}$.

The relative fuel burnup rates in other fuel rods and the respective neutron fluxes experienced by these rods during the entire irradiation, as well as portions of such irradiations, can be interpreted similarly with the aid of tables of $R$ values and Figures 6 through 10. Analyses of this nature reveal that the maxima of both $R$ values and their ratio with respect to $R_{137}$ occur at different axial positions in different fuel rods. In addition, a change in these maximum activity positions occurred during the irradiation period: The former is attributable to the position of the rods in a fuel assembly and the location of the assembly containing the fuel rod within the core of a reactor. The latter, nameily changes in the position of maximum fuel burnup rates during irradiation, is associated with the power drift along the fuel rod axis.

The absolute fuel burnup determined by radiochemical analys is of two transverse sections of each fuel rod represent values for the entire irradiation. Therefore, the relative axial concentration profiles of ${ }^{137} \mathrm{Cs}, \mathrm{R}_{137}$, are employed in evaluating conversion factors to construct absolute fuel burnup profiles. Since two sections of each rod were analyzed radiochemically, it is more appropriate to utilize an average of the conversion factors calculated for the 
two axial positions in converting relative values to absolute fuel burnup profiles. These average values of conversion factors are given in Table 9.

The axial locations of samples that were analyzed by radiochemical methods are identified relative to the bottom of the fuel rods. The axial positions in determining relative fuel burnup profiles, on the other hand, are referenced relative to the bottom of the fuel pellet stack that was detected with ease in the gamma scans. Therefore, it is necessary to rationalize the two different reference positions. This was achieved with the help of the specification drawings of the fuel rod assemblies. It was determined from the available schematic that the bottom position of the fuel pellet stack is located 15.24 $\mathrm{cm}(6.0 \mathrm{in.})$ from the bottom of the fuel rods.

The relative atomic composition of irradiated mixed oxide fuel rods (Table 8 ) is based, as explained earlier, on mass and gamma spectroscopic data. The number of atoms of ${ }^{238} \mathrm{U}$ remaining in the fuel after irradiation is chosen as an internal reference. The atomic abundance of ${ }^{237} \mathrm{~Np}$ based on the intensity of its characteristic gamma ray, $86.5 \mathrm{keV}$, appears to yield rather high values. All possible interferences with and sources of this gamma ray were considered but no reasonable explanation could be found. At the same time, it is rot possible to identify the source of this isotope to justify its observed abundance in the fuel samples analyzed. 
Table 9. Absolute Fuel Burnup and Conversion Factors for Mixed Oxide Fuel Rods

\begin{tabular}{|c|c|c|c|c|c|c|c|}
\hline \multirow[b]{2}{*}{$\begin{array}{l}\text { Sample } \\
\text { number } \\
\end{array}$} & & & \multirow{2}{*}{$\begin{array}{l}\text { Relative }(b) \\
\text { activity }(b) \\
\text { of } 137 \mathrm{Cs} \\
\left(\mathrm{R}_{137}\right) \\
\end{array}$} & \multicolumn{3}{|c|}{ Fuel burnup } & \multirow{2}{*}{$\begin{array}{l}\text { Average } \\
\text { fue } 1 \text { burnup } \\
\text { at } \% \text { per } \\
\text { unit, } R_{137} \\
\end{array}$} \\
\hline & $\frac{\text { Axiai }}{\mathrm{cm}}$ & $\frac{\text { ition }}{\text { Incries }}$ & & $\begin{array}{c}\mathrm{Nd} \\
\text { method }\end{array}$ & $\underline{G W d / m t}$ & $\begin{array}{l}\text { Per unit } \\
\text { rel. act. }\end{array}$ & \\
\hline $97-A$ & 250.19 & 98.5 & 0.699 & -- & -- & - & $\therefore$ \\
\hline $97-B$ & 77.47 & 30.5 & 0.974 & 1.68 & 16.14 & 1.725 & 1.725 \\
\hline $98-A$ & 250.19 & 98.5 & 0.760 & 1.92 & 18.48 & 2.525 & \multirow{2}{*}{$2.630 \pm 0.105$} \\
\hline $98-B$ & 77.47 & 30.5 & 0.936 & 2.56 & $24: 53$ & 2.735 & \\
\hline $99-A$ & 247.65 & 97.5 & 0.740 & 1.47 & 14.10 & 1.986 & \multirow{2}{*}{$2.22 \pm 0.234$} \\
\hline 99-B & 80.01 & 31.5 & 0.970 & 2.38 & 22.82 & 2.454 & \\
\hline $100-A$ & 247.65 & 97.5 & 0.711 & 1.06 & 10.18 & 1.491 & \multirow{2}{*}{$1.529 \pm 0.137$} \\
\hline $100-B$ & 80.01 & 31.5 & 0.940 & 1.66 & 15.93 & $1.766^{\circ}$ & \\
\hline $101-A$ & 247.65 & 97.5 & 0.773 & 1.40 & 13.49 & .1 .811 & \multirow{2}{*}{$1.751 \pm 0.140$} \\
\hline 101-B & 80.01 & 31.5 & 0.914 & 1.91 & 18.38 & 1.090 & \\
\hline $102-A$ & 247.65 & 97.5 & 0.779 & 1.22 & 11.69 & $\therefore .566$ & \multirow[b]{2}{*}{$1.493 \pm 0.073$} \\
\hline $102-B$ & 80.01 & 31.5 & 0.958 & 1.36 & 13.06 & 1.420 & \\
\hline
\end{tabular}

(a) From bottom of fuel rod (Table 1).

(b) From Tables 2 through ?. 


\section{CONCLUSIONS}

It was shown here that the $R$ values of primary fission products represented the relative fuel burnup profiles. The burnup profiles during various segments of the irradiation period can be established by choosing a number of fission products with different half-lives, thus providing a method to unfold the overall burnup profile represented by the $R$ value of a long-lived fission product such as ${ }^{137} \mathrm{Cs}$.

The axial distribution of a neutron capture product, ${ }^{134} \mathrm{Cs}$, was shown to represent the square of the time-averaged neutron flux while the ratio, $R_{134} / R_{137}$, signified the time-averaged neutron flux itself. This provides an avenue to determine the distribution of neutron fluxes along fuel rod axes for the entire irradiation period. Statistical analyses of this nature are worthwhile endeavors for obtaining information on neutron fluxes experienced by fuel assemblies and fuel elements.

The axial position of maximum $R$ values used in the interpretation of results from the gamma scan technique was one of the 10 locations at which gamma spectra were recorded and analyzed. It is, therefore, conceivable that the true positions of maximum $R$ values were not identified. This can be ascertained. either by recording and analyzing gamma spectra at closer intervals or by fitting the observed pairs of activities and axial positions to an analytical function.

In the former approach, the precision of measurement is determined by the duration for which the gamma spectrum was stored during analysis as the fuel rod is scanned continuously at a uniform rate. However, adaptation of this technique should await the design and development of more reliable hardware and software. The latter method of establishing an anaiytical function of activity versus axial position based on a finite number of observations is easily adaptable. Even though this has not been done in the present investigation, results from similar work currently in progress at the Lynchburg Research Center appear to be promising. 


\section{REFERENCES}

1 N. Vignesoult, et al., "Remote Controlled Inspection Techniques for Investigation of Fission Product Behavior," Proc. 20th Conference on Remote Systems Technology, 1972.

2 J. R. Phillips, et al., "The Use of High-Resolution Gamma Ray Spectrometry for Detecting Failure of Cladding in Encapsulated Fast Reactor Fuel Pins," Proc. 19th Conference on Remote Systems Technology, 1971.

3. S. Matsuura, et al., "Non-Destructive Gamma Ray Spectrometry on Spent Fuels of a Boiling Water Reactor," J. Nucl. Sci. Tech., 12(1) (1975), pp 24-34.

4 R. D. Evans, "The Atomic Nucleus," Chap. 15, McGraw-Hill Book Company, New York, New York (1967).

5 H. Tsuruta, et al., "Profiles of Activity Ratios of Fission Products, Cesium134, Cesium-137, and Ruthenium-106 in Low Enriched $\mathrm{PuO}_{2}-\mathrm{UO}_{2}$ Fuel Assemblies," J. Nucl. Sci. Tech., 14(1) (1977), pp 43-53.

6 G. M. Bain, Private Communication. 
Copy No.

General Atomic Corporation

Bresnick, SD (5) 1-5

Babcock \& Wilcox

Power Generation Group, Lynchburg

Library

Travis, CC/TRG

Contract Research Division

Lukasik, M

R\&D Division, Lynchburg

$\begin{array}{lc}\text { Corporate Information Center } & 9 \\ \text { Davis, HH } & 10 \\ \text { Hardt, TL } & 11 \\ \text { Irradiation Materials } & 12-13 \\ \text { Technology (2) } & 14 \\ \text { Library/LRC } & 15 \\ \text { Nuclear \& Radiochemistry } & 16-17 \\ \text { Rigdon, MA (2) } & 18 \\ \text { Rowe, JP } & 19 \\ \text { St. John, JD } & 20 \\ \text { Subrahmanyam, V } & \end{array}$




\section{APPENDIX C \\ DISTRIBUTION}

No. of

Copies

U. S. Department of Energy

Chicago Operations and Regional office

Acquisition and Assistance

9800 South Cass Avenue

Argonne, Illinois 60439

Attn: Thomas R. Katisch, Director . . 5

Argonne National Laboratory

9700 South Cass Avenue

Argonne, Illinois 60439 . . . . . . . . . 1

Battelle Memorial Institute

Pacific Northwest Laboratory

P.O. Box 999

Richland, Washington 99352 . . . . . . 1

Oak Ridge National Laboratory

P.0. Box X

Oak Ridge, Tennessee 37830 . . . . . . . 1

Allied General Nuclear Service

P.0. Box 847

Barnwe11, South Carolina 29812

Attn: Jim Buckhaiu . . . . . . . . 1

Generà1 Atomic Company

P.O. Box 81608

San Diego, California 92138

Attn: R. Zimmerman . . . . . . . . 2

Hartford Engineering Development Laboratory

P.0. Box 1970

Richland, Washington 99352 . . . . . . 1

Idaho National Engineering Laboratory

550 Second Street

Idaho Falls, Idaho 83401 . . . . . . . 1 


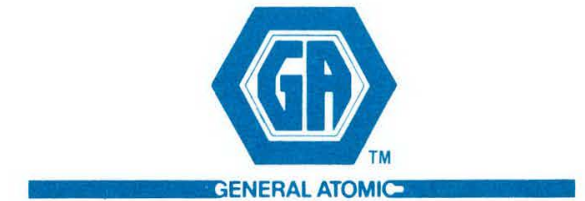

GENERAL ATOMIC COMPANY P. O. BOX 81608

SAN DIEGO, CALIFORNIA 92138 